\title{
Synthesis of Hierarchical ZSM-5 Zeolites by Solid-State Crystallization and Their Catalytic Properties
}

${ }^{1}$ Chemical Engineering, Institute for Micromanufacturing, Louisiana Tech University, 911 Hergot Avenue, Ruston, LA, 71272, USA.

${ }^{2}$ Key Laboratory of Fine Chemicals of Universities in Shandong, School of Chemistry and

7 Pharmaceutical Engineering, Qilu University of Technology, Jinan 250353, PR China.

8 Corresponding Author: Shengnian Wang, 318-257-5125, swang@, latech.edu

9 KEYWORDS: zeolites, mesoporous materials, solid-state crystallization, lignin 10 depolymerization, hydrogenation

ABSTRACT: Hierarchically porous structure is important to promote mass transport and active site utilization of zeolites for many petrochemical reactions involving bulky molecules. Their conventional hydrothermal synthesis with meso-template materials is often complicated, expensive, and produces a large amount of aqueous pollute. We demonstrate here successful synthesis of mesoporous zeolites of MFI structure by solid-state crystallization without mesotemplate. Aluminosilicate nanogels are produced with only precursors and the dried nanoparticles are then transformed into nanocrystals in solid state using only their intrinsic water storage. After orientating with each other at edges, these nanocrystals joint into monolithic zeolites with connecting inter-lattice mesopores. The produced hierarchical ZSM-5 zeolites exhibit superior stability and excellent catalytic performance in reactions like Friedel-Crafts benzylation, lignin ethanolysis, and naphthalene hydrogenation. Compared with conventional synthesis routes, this new solid crystallization approach simplifies zeolite production, lowers the cost, and avoids toxic liquid waste, which may greatly benefit many energy applications.

\section{Introduction}

Zeolites are crystalline aluminosilicates widely used as heterogeneous catalyst in different crude oil upgrading and chemical refinery processes.[1-3] The strong acidity and uniform micropores $(<2 \mathrm{~nm}$ in diameter) defined by their unique crystal structure enables superior selectivity based on shape and/or chemical configuration of molecules in various

30 chemical reactions including alkylation, aromatization, cracking, pyrolysis, and 31 hydrodesulfurization.[4-6] However, when bulky reactants/products are involved, this is often 32 accompanied with serious diffusion problem inside zeolite crystalline and consequent pore 33 blocking issues in both traditional petrochemical processes and the emerging renewable bio34 energy processes.[7-9] Introducing mesopores (2-50 $\mathrm{nm}$ in diameter) or staged hierarchical 
porosity (i.e., connected macropores, mesopores, and micrpores) is considered as a promising solution to such limited molecule transport and low active site utilization issues in zeolites.[1013] Various synthesis routes, including both post-treatment and template assembly, have been developed to produce hierarchically porous zeolites.[14-34] The former (post-treatment approach) obtains mesoporous structure by selectively leaching $\mathrm{Si}$ or $\mathrm{Al}$ atoms out of the zeolite crystal framework,[17-19] while the latter (template synthesis approach) pre-reserves the hierarchical space with either hard nanomaterials or surfactant-like macromolecules during the assembly or crystallization.[20-28] Compared to the inevitable change on the acidity and crystalline framework of zeolites in post treatment approaches, these properties are well preserved in the template synthesis processes. However, the template synthesis approaches often suffer from issues like the availability or synthesis challenges of desired template molecules [2931], as well as their compatibility with precursors.[32-34] No matter which strategy is adopted, traditional hydrothermal synthesis process is essential in zeolite production, which requires the use of a large quantity of solvent (e.g., water and ethanol) while often results in incomplete crystallization with a yield of $\sim 80 \%$ or less zeolites. [35] This leaves a significant amount of toxic liquid waste containing alkali, silicates, and aluminates, which not only increases the total cost for post-synthesis separation, but also results in consequent healthy issues and environmental pollution. [36] Such issues become more serious in many emerging biomassbased renewable energy processes with their significantly high quantity demand of zeolites (with a catalyst-to-reactant ratio often larger than 1:1). [37] This could largely offset the potential benefits of these bioenergy routes considering the new pollution concerns or negative impact to environment initiated by the involved zeolite industry. All of these facts stimulate great desire to look for new, low-cost, and environmental benign strategies in hierarchical zeolite synthesis.

We report here a new synthesis route to effectively produce hierarchical zeolites with MFI structure that requires neither help of meso-template materials nor solvent-involved crystallization environment. The synthesis details are illustrated schematically in Figure 1. In this approach, aluminosilicate nanogels are firstly prepared by a sol-gel process at relatively low 28 temperature, involving only precursor compounds. After evaporating the solvent (i.e., water and ethanol) at room temperature, the dry nanogels are transferred to a Teflon-lined autoclave and calcined without adding water or any other solvent. During this solid phase crystallization process, the amorphous aluminosilicates are transformed slowly using water stored in individual nanogels. Accompanied with hydrolysis and condensation of Si-Al tetrahedral, adjacent nanogels are brought together as large ensembles simultaneously by weak, solid-solid interactions. With 34 the crystallization extending to the edge of nanogels, the new formed crystals over there align their crystalline patterns to the surrounding nanocrystals and eventually joint into a single piece, large crystalline zeolite. The stacking of these nanocrystals creates many inter-lattice mesoscale 


\section{Stage I: Aluminosilicate Nanogels}
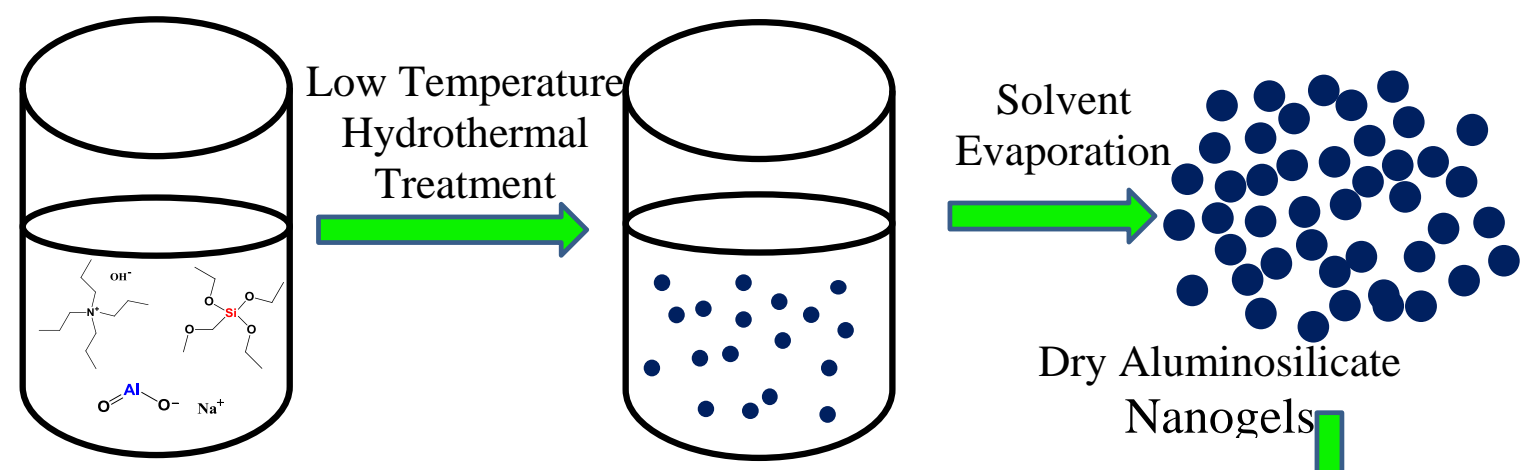

Dry Aluminosilicate

Nanogels

\section{Stage II: Solid-state Crystallization}
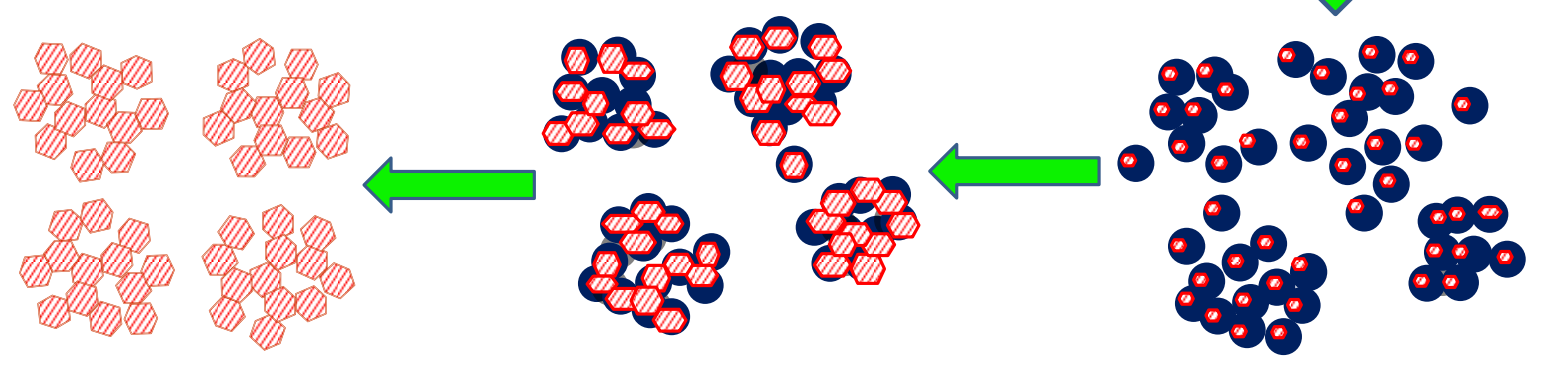

Figure 1. Schematics of the meso-template free synthesis and solid state crystallization route towards hierarchically zeolites, Meso-ZSM-5.

\section{Materials and Methods}

\subsection{Materials}

Tetrapropyl ammonium hydroxide (TPAOH, $1 \mathrm{M}$ in $\left.\mathrm{H}_{2} \mathrm{O}\right)$, sodium aluminate $\left(\mathrm{NaAlO}_{2}\right.$, $\sim 8 \% \mathrm{H}_{2} \mathrm{O},>99 \%$ ), tetraethylorthosilicate (TEOS, >99\%), benzene $(>99 \%)$, benzyl alcohol ( $>99 \%$ ), lignin (alkali), ethanol $\left(\mathrm{C}_{2} \mathrm{H}_{5} \mathrm{OH},>99.5 \%\right)$, naphthalene $\left(\mathrm{C}_{10} \mathrm{H}_{8},>99 \%\right)$, n-hexadecane $\left(\mathrm{n}-\mathrm{C}_{16} \mathrm{H}_{34},>99 \%\right)$ were purchased from Sigma-Aldrich and used as received without further

10 purification.

\section{$11 \quad 2.2$ Zeolite Synthesis}

Meso-ZSM-5 zeolites were synthesized by mixing TPAOH, $\mathrm{NaAlO}_{2}$, TEOS, and $\mathrm{H}_{2} \mathrm{O}$ with a molar ratio of $0.25 \mathrm{TPAOH}: 0.03 \mathrm{Al}_{2} \mathrm{O}_{3}: \mathrm{SiO}_{2}: 80 \mathrm{H}_{2} \mathrm{O}$. TPAOH and $\mathrm{NaAlO}_{2}$ were first dissolved in $\mathrm{H}_{2} \mathrm{O}$, followed by adding TEOS under strong agitation (i.e., $600 \mathrm{rpm}$ ). The mixture was kept at $80{ }^{\circ} \mathrm{C}$ until a clear solution was obtained, which was left in hood overnight at room temperature allowing for solvent evaporation. The dry gel was then collected and ground into 
powders and the as-prepared dry gel powders were further transferred to a Teflon-lined autoclave for crystallization at $140{ }^{\circ} \mathrm{C}$ for $12 \mathrm{~h}$ without adding any water. Note: autoclave or other highpressure vessel is not mandatory in this solid-state crystallization process as no significant pressure is generated, unlike the traditional hydrothermal or steam-assisted crystallization in which 1-4 MPa steam pressure presents in autoclave, depending on the filling volume. [38, 39] Here, containers that are capable of tight seal at elevated temperature (e.g., air-tight glass or plastic lab bottles) and resistant to basic liquid can be used. Autoclaves were used here for the comparison convenience with the hydrothermal synthesis of microporous ZSM-5 (e.g., considering the consistence on internal temperature, the heating and cooling rates). Without washing, the fully crystallized zeolites were dried at $100^{\circ} \mathrm{C}$ for $4 \mathrm{~h}$ to remove the adsorbed water and calcined at $500^{\circ} \mathrm{C}$ for $6 \mathrm{~h}$ (at a heating rate of $1{ }^{\circ} \mathrm{C} / \mathrm{min}$ ) for structure stabilization and the removal of TPAOH. Conventional ZSM-5 zeolites with a similar Si/Al ratio (i.e., 33) were synthesized via traditional hydrothermal method at $140^{\circ} \mathrm{C}$ for $48 \mathrm{~h}$.

All zeolite samples were ion-exchanged three times with a $0.1 \mathrm{M} \mathrm{NH}_{4} \mathrm{NO}_{3}$ solution at 90 ${ }^{\circ} \mathrm{C}$ for $90 \mathrm{~min}$ with a liquid/solid ratio of $10 \mathrm{~cm}^{3} / \mathrm{g}$ under magnetic agitation $(500 \mathrm{rpm})$. After that, samples were filtered, extensively washed with distilled water, and dried at $100{ }^{\circ} \mathrm{C}$ for $4 \mathrm{~h}$.

\subsection{Pt/Zeolite Catalyst Preparation}

Pt/ZSM-5 and Pt/Meso-ZSM-5 catalysts were prepared by conventional incipient wetness impregnation. In brief, an $\mathrm{H}_{2} \mathrm{PtCl}_{6} \cdot 6 \mathrm{H}_{2} \mathrm{O}$ (99\%, Sigma-Aldrich) aqueous solution ( $10 \mathrm{~mL}$, containing $\left.26.6 \mathrm{mg} \mathrm{H}_{2} \mathrm{PtCl}_{6} \cdot 6 \mathrm{H}_{2} \mathrm{O}\right)$ was added dropwise to wet $\mathrm{H}$-type zeolite powder $(1.0 \mathrm{~g})$ at room temperature and the suspension was further diluted with DI water to a total volume of 50 $\mathrm{mL}$ under agitation (200 rpm). After 3 hour of stirring, the suspension was left still, allowing for solvent evaporation. The dried catalyst were then transferred to a furnace for further drying at $120{ }^{\circ} \mathrm{C}$ for $12 \mathrm{~h}$ and calcined at $500{ }^{\circ} \mathrm{C}$ for $4 \mathrm{~h}$ (with a heating rate of $1.5^{\circ} \mathrm{C} / \mathrm{min}$ ). Dried catalyst was reduced in a flow of $\mathrm{H}_{2}$ for $3 \mathrm{hr}$ at $450{ }^{\circ} \mathrm{C}$, using a heating rate of $2.5^{\circ} \mathrm{C} / \mathrm{min}$ prior to use.

\subsection{Characterization}

X-ray diffraction (XRD) analysis was done on a Bruker D8 diffractometer, using $\mathrm{Cu}-\mathrm{K} \alpha$ radiation at room temperature and instrumental settings of $40 \mathrm{kV}$ and $40 \mathrm{~mA}$. Data were recorded in the $2 \theta$ range of $5-60^{\circ}$ with an angular step size of $0.02^{\circ}$. The crystallinity of the synthesized zeolites was quantified by taking the value of the integrated area from the XRD peaks in the $2 \theta$ range of $22.5-25^{\circ}$. These peaks appeared early during the crystallization process with clear peak boundary for accurate calculation. The relative crystallinity of Meso-ZSM-5 was calculated by comparing their integrated peak area with that of purely microporous zeolite ZSM-5 as:

$$
\% \text { Crystallinity }=\frac{\text { Peak Area }(\text { sample of Meso-ZSM-5) }}{\text { Peak Area }(\text { Reference ZSM-5) }} \times 100 \% \text {. }
$$


Solid-state magic angle spinning nuclear magnetic resonance (MAS NMR) spectra were recorded with a single pulse experiment on a 9.4T $(400 \mathrm{MHz} 1 \mathrm{H})$ wide bore magnet using Bruker AV console and $4 \mathrm{~mm}$ probe. The ${ }^{29} \mathrm{Si}$ experiments were done with single $4-\mu$ s pulse, a relaxation delay of $60 \mathrm{~s}$, and a MAS spinning rate of $8 \mathrm{kHz}$. Each ${ }^{29} \mathrm{Si}$ spectrum was collected with 256 scans. The ${ }^{27} \mathrm{Al}$ experiments were done with a pulse length of $0.33 \mu$ s, a recycle delay of $0.1 \mathrm{~s}$, and $14 \mathrm{kHz}$ MAS rate. Each ${ }^{27} \mathrm{Al}$ spectrum was collected with 4096 scans. The ${ }^{29} \mathrm{Si}$ and ${ }^{27} \mathrm{Al}$ spectra were reported relative to tetrakis (trimethylsilyl)silane (TTMSS) and $\mathrm{Al}\left(\mathrm{NO}_{3}\right)_{3}$, respectively. Some NMR spectra were deconvoluted using Gaussian function.

Scanning electron microscopy (SEM) images were taken on a Hitachi S-4800. Samples were prepared by dusting the zeolite powder onto double sided carbon tape, mounted on an alumina stub. All samples were subsequently sputter coated with a thin gold film to reduce charging effects. Transmission electron microscopy (TEM) and selected-area electron diffraction (ED) measurements were carried out on a JEOL 2010F instrument, operating at $200 \mathrm{kV}$. The samples were suspended in ethanol and dispersed on a copper grid coated with lacey carbon film before TEM analysis.

Nitrogen adsorption isotherms were obtained at $-196{ }^{\circ} \mathrm{C}$ on a Micromeritics ASAP 2020 Surface Area and Porosity Analyzer in a relative pressure range from 0.05 to 0.99 . Before measurement, samples were degassed at $300{ }^{\circ} \mathrm{C}$ for $6 \mathrm{~h}$. The pore size distribution was calculated using the Nonlocal Density Functional Theory (NLDFT) method from the adsorption branch.

The ammonia temperature programmed desorption $\left(\mathrm{NH}_{3}-\mathrm{TPD}\right)$ was used to measure the acidity of zeolites on a Micromeritics AutochemII Chemisorption Analyzer. Zeolite materials (50 $\mathrm{mg}$ ) was pretreated at $300^{\circ} \mathrm{C}$ for $1 \mathrm{~h}$ and then cooled down to $50^{\circ} \mathrm{C}$ in an Ar flow of $20 \mathrm{~cm}^{3} / \mathrm{min}$. Pure $\mathrm{NH}_{3}$ (at a flow rate of $20 \mathrm{~cm}^{3} / \mathrm{min}$ ) was injected until adsorption saturation, followed by $\mathrm{Ar}$ purging for another $1 \mathrm{~h}$. The desorption of $\mathrm{NH}_{3}$ was monitored in the range of $50-700^{\circ} \mathrm{C}$ with a ramp of $10^{\circ} \mathrm{C} / \mathrm{min}$ by a TCD detector.

Thermo-gravimetric analysis (TGA) was used to quantify water carried by dry nanogel powder to the second solid-state crystallization step using a TGA 2050 Thermogravimetric Analyzer (TA Instruments, Inc). To distinguish water left in dry nanogel from those through adsorption, some dry nanogel powders were left in a high-purity argon-filled glove box (with water content $<0.1 \mathrm{ppm}$ ) for a week to remove the adsorbed water in nanogels. The weight loss of nanogel samples was monitored through a thermal scanning from 30 to $110^{\circ} \mathrm{C}$ at a ramp rate of $10{ }^{\circ} \mathrm{C} / \mathrm{min}$ in air atmosphere.

\subsection{Catalytic reaction tests}

The benzylation of benzene with benzyl alcohol was carried out at $80{ }^{\circ} \mathrm{C}$, with $0.15 \mathrm{~g}$ catalyst, $34 \mathrm{~mL}$ benzene, and $0.5 \mathrm{~mL}$ benzyl alcohol in a three-necked round-bottom flask equipped with a reflux condenser. Samples were taken every hour and analyzed by gas chromatography (VARIAN CP-3800 GC with an FID detector using a $30 \mathrm{~m}$ packed HP-5 
The catalytic conversion of Kraft lignin was carried out at $280{ }^{\circ} \mathrm{C}$ for $6 \mathrm{~h}$ in a highpressure batch reactor (Col-Int Tech, $200 \mathrm{~mL}$ ). For each run, $1.0 \mathrm{~g}$ lignin, $0.5 \mathrm{~g}$ catalyst, and 100 $\mathrm{mL}$ ethanol were first loaded in the reactor and the sealed reactor was then evacuated and purged with high-purity nitrogen gas for three times at room temperature. The reactor temperature was then risen to $280^{\circ} \mathrm{C}$ with the reactor pressure reaching $\sim 8 \mathrm{MPa}$. After the reaction was carried out for $6 \mathrm{~h}$, the liquid was filtered and taken for product identification and analysis on a GC-MS instrument (Agilent 7890A-5975C). Benzyl alcohol (0.1 vol\% in ethanol, $1.0 \mu \mathrm{L})$ was added in the product samples $(1 \mathrm{~mL})$ before GC-MS analysis, serving as the known internal standard in GC-MS spectra to normalize the peak area for each compound. Multiple-point internal standard plots were generated, covering the expected concentration range of major product compounds. For those commercially available compounds, such as 4-methyl phenol (i.e., cresol) and 2methoxy-phenol (i.e., GUA), diluted solutions with known concentrations were prepared. For other commercially-not-available compounds like 3-methyl-1- adamantaneacetic acid, the lignin depolymerization product obtained from different catalysts were mixed and further concentrated by evaporating most ethanol using a rotary evaporator. The obtained liquid was then diluted with ethanol to get different concentrations of each compound using benzyl alcohol as the internal standard $(0.8 \mathrm{mM})$. Plots of the peak area ratio of several major aromatic compounds in lignin depolymerisation products to the internal standard (benzyl alcohol) were made versus the concentration ratio (supplemental Figures $1 \mathrm{a \& b}$ ). The original concentrations of those commercially-not-available compounds in the mother solution were determined by their area ratios to GUA whose concentration in samples were found through their own multiple-point internal standard curve (supplemental Figure 1a). The solid was collected and weighted to calculate the overall lignin conversion.

The hydrogenation of naphthalene on Pt/ZSM-5 and Pt/Meso-ZSM-5 catalysts was performed in a large high-pressure batch reactor (Col-Int Tech, $400 \mathrm{~mL}$ ). As the hydrogenation of naphthalene and its intermediate product (i.e., tretalin) is exothermic, the generated heat can be quickly removed by the internal cooling coil of this bigger reactor to maintain the reaction temperature. It also allows taking samples while the reactor is in operation at elevated temperature and pressure conditions to obtain the reaction kinetics. For each experiment, $33 \mathrm{mg}$

30 of naphthalene was dissolved in n-hexadecane (99\%, Sigma-Aldrich) of $100 \mathrm{~mL}$ and the solution was loaded in the reactor, together with $0.5 \mathrm{~g}$ catalyst. After loading, the reactor was sealed tightly and the stirring speed was set to $1,000 \mathrm{rpm}$. The reactor was heated with an electric heating jacket to the desired temperature $(\sim 1 \mathrm{hr})$ and the hydrogenation was studied at $200^{\circ} \mathrm{C}$

34 with a hydrogen pressure of 7.5 MPa. Samples were taken every hour of a total of 5 hour 35 reaction period and were filtered through a syringe filter prior to GC-MS analysis.

\subsection{Solid State Crystallization Evolution and Textural Properties}


To reveal such solid-state crystallization evolution, aluminosilicate intermediates at different synthesis moments were examined with SEM, XRD and NMR. The nanogels collected after stage I synthesis have an average size of $\sim 20-30 \mathrm{~nm}$ (Figure 2a) and are amorphous (Figure 3 ). After crystallizing in a solvent-free environment for $3 \mathrm{~h}$, these nanogels started aggregating in some locations with unclear boundaries (Figure $2 b$ ) while the majority stayed amorphous (Figure 3 ). When the crystallization proceeded to $6 \mathrm{~h}$, weak crystalline peaks appeared (Figure 3a) with a relative crystallinity of $\sim 40 \%$ (Figure $3 \mathrm{~b}$ ). More aluminosilicate ensembles were found with defined boundaries (Figure 2c). All MFI peaks with strong, clearly defined pattern were first shown after 9-hour crystallization (Figure 3 ) with a relative crystallinity close to $\sim 90 \%$ (Figure 3b). Large nanoparticle ensembles with clear boundaries and uniform size were seen everywhere (Figure 2d). With a total of 12-hour crystallization, the XRD pattern stayed the same without

12 further increase on the intensity of individual peaks (Figure 3a). Further extending the crystallization time was found no change on the crystallinity degree (Figure 3b), indicating that fully crystallized zeolites are obtained after the 12-hour, solid-state crystallization. These large zeolites have similar spherical shape, uniform particle size ( $400 \mathrm{~nm}$ in diameter), and very rough surface (Figure 2e). The high magnification SEM image (Figure 2f) further reveals that they are highly mesoporous, attributed to the assembly of many nanoparticles of 20-30 nm. The high-resolution TEM (HRTEM) image further tells that these are nanosized crystals (Figure 4a). Considering their similar size to the original aluminosilicates nanogels, we believe each monolithic zeolite nucleates simultaneously from many individual nanogels. The formed small nanocrystals exhibit lattice fringes of the same orientation (Figures $4 a$ and $4 b$ ), suggesting that these nanocrystals have been grown and merged into a single, large monolithic crystal rather than randomly packed nanocrystal aggregates. The electron diffraction spot pattern of a selectedarea in HRTEM image (inset of Figure 4a) evidences this fact. The jointed nanocrystals create many inter-lattice mesopores in zeolite crystalline frameworks (Figures $4 \mathrm{a}$ and $4 \mathrm{~b}$ ). With the XRD pattern of these zeolites matching that from a conventional microporous ZSM-5 sample and in good agreement with the database MFI structure (Figure 4c), we conclude the successful synthesis of mesoporous ZSM-5 with this new solid-state crystallization approach (denoted as Meso-ZSM-5 in later discussions). Although slightly broader XRD peaks were seen in these Meso-ZSM-5 samples to the microporous ZSM-5 due to the small individual crystallites (Figure 4d), their jointed framework as single, monolithic pieces of crystallites of $400 \mathrm{~nm}$ largely offsets any pronounced peak broadening effect often seen in physical aggregates of nanosized zeolites. Therefore, identical XRD patterns with similar peak width are found in Meso-ZSM-5 and microporous ZSM-5 of similar crystal sizes $(400-500 \mathrm{~nm})$.

Although these unique textural features are clearly shown by SEM and TEM, quantifying such properties is not trivia due to its staged hierarchical porosity (i.e., connected macropores, mesopores, and micrpores). [40] The $\mathrm{N}_{2}$ adsorption-desorption isotherm of the Meso-ZSM-5 zeolites sample was obtained, which exhibits features of both type I and type IV(a) profiles with two steep uptake steps, one at $\mathrm{P} / \mathrm{P}_{0}<0.02$ and the other at $0.45<\mathrm{P} / \mathrm{P}_{0}<0.90$ locations, responding for micropore filling and mesopore capillary condensation, respectively (Figure 4e). 
1 In contrast, the conventional ZSM-5 shows a typical type-I isotherm with only one high uptake at 2 low relative pressures $(\mathrm{P} / \mathrm{P} 0<0.02)$ and a long plateau at high relative pressures $(0.4<\mathrm{P} / \mathrm{P} 0<$ 3 0.9), indicating that the material is a purely microporous phase with negligible mesoporosity. 4 Together with this additional high uptake of the type-IV(a) profile, the appearance of a typical 5 H4 hysteresis loop on the isotherm of typical mesoporous materials at high relative pressure 6 further confirm the existing of both microporosity and mesoporosity in our synthesized Meso7 ZSM-5. This $\mathrm{H} 4$ loop with more pronounced uptake at low $\mathrm{P} / \mathrm{P} 0$ than $\mathrm{H} 1$ or $\mathrm{H} 2$ is in consistence 8 with the adsorption-desorption isotherms of aggregated nanocrystals of zeolites. [41] In the 9 NLDFT pore size distribution plot, a very sharp peak centered at $3.0 \mathrm{~nm}$, followed by a weak, 10 broad peak centered at $9 \mathrm{~nm}$ is found for this Meso-ZSM-5 sample (Figure 4f). The long tail of 11 the second peak could be the result of mismatching between the actual pore structure and the 12 available model pore shapes. Nonetheless, it endorses the existing of mesopores in Meso-ZSM-5. 13 In contrast, only the first peak centered at $2.0 \mathrm{~nm}$ is shown in the NLDFT plot for traditional 14 ZSM-5 sample, in consistence with its sole microporous structure. Although the use of 15 traditional BET approach to extract surface area and pore volume information from these $\mathrm{N}_{2}$ 16 adsorption-desorption isotherms is known inappropriate for most zeolites, such results are 17 provided as a table in the supplemental document for general reference purpose, considering its 18 popular use for textural property measurement of zeolites in history and in case, some 19 comparisons with data from other researchers are needed. 

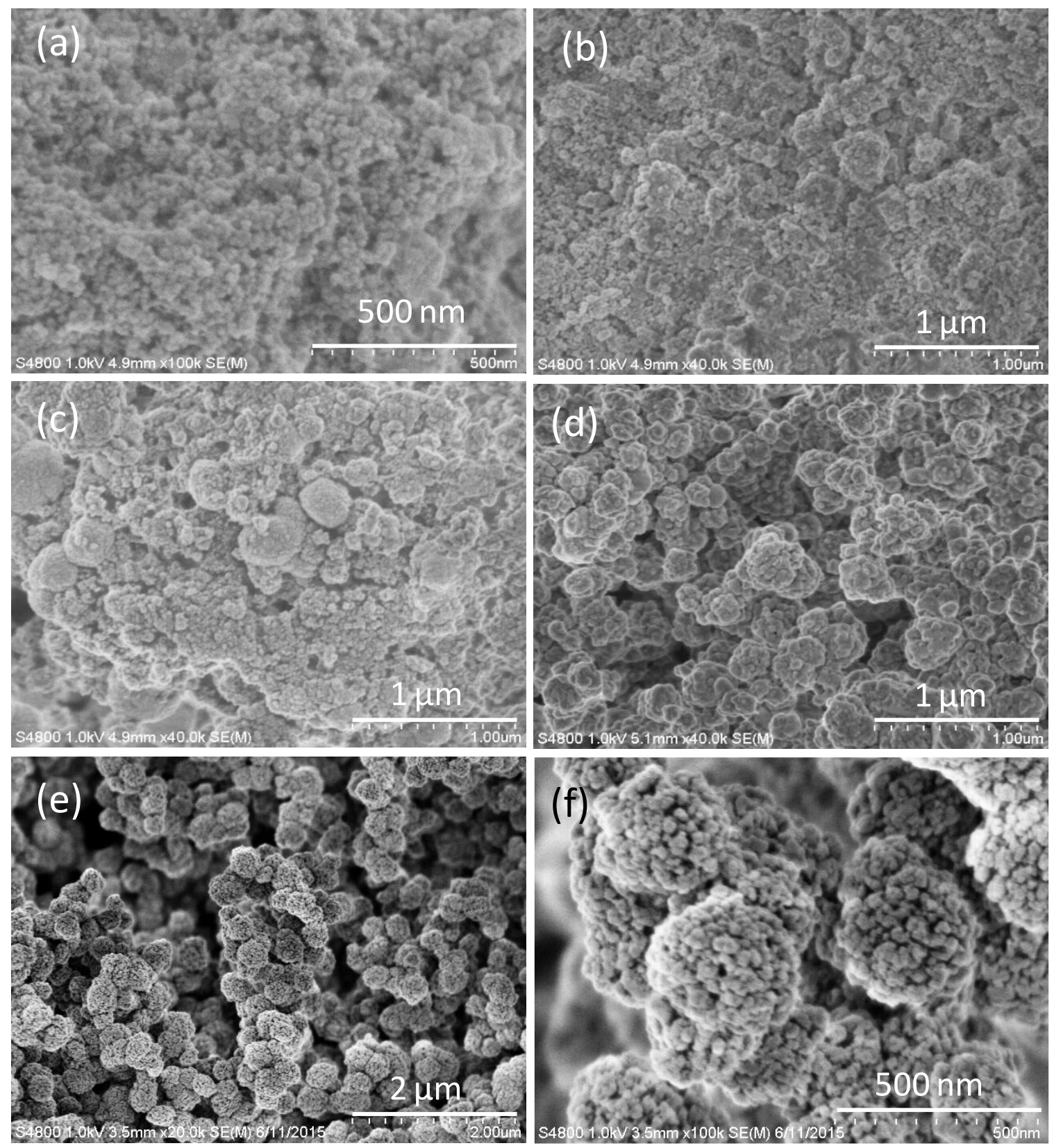

2 Figure 2. SEM of the aluminosilicate particle samples that have been crystallized for (a) $0 \mathrm{~h}$, (b)

$33 \mathrm{~h},(\mathrm{c}) 6 \mathrm{~h},(\mathrm{~d}) 9 \mathrm{~h}$, and (e, f) $12 \mathrm{~h}$. 
(a)
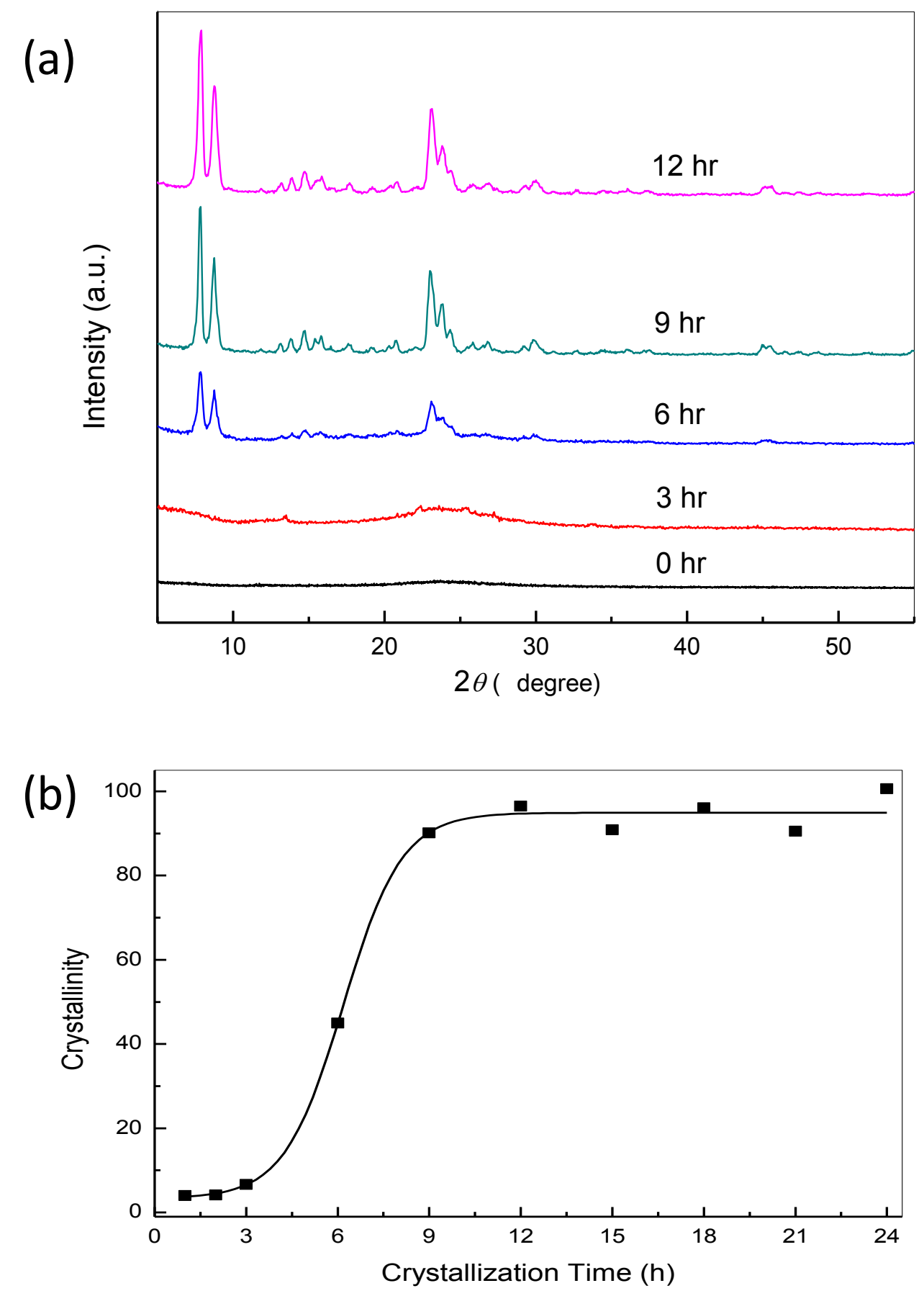

2

3 Figure 3. (a) XRD patterns of the aluminosilicate particle samples that have crystallized for $0 \mathrm{~h}$, $43 \mathrm{~h}, 6 \mathrm{~h}, 9 \mathrm{~h}$, and $12 \mathrm{~h}$ and (b) the relative crystallinity kinetics. 

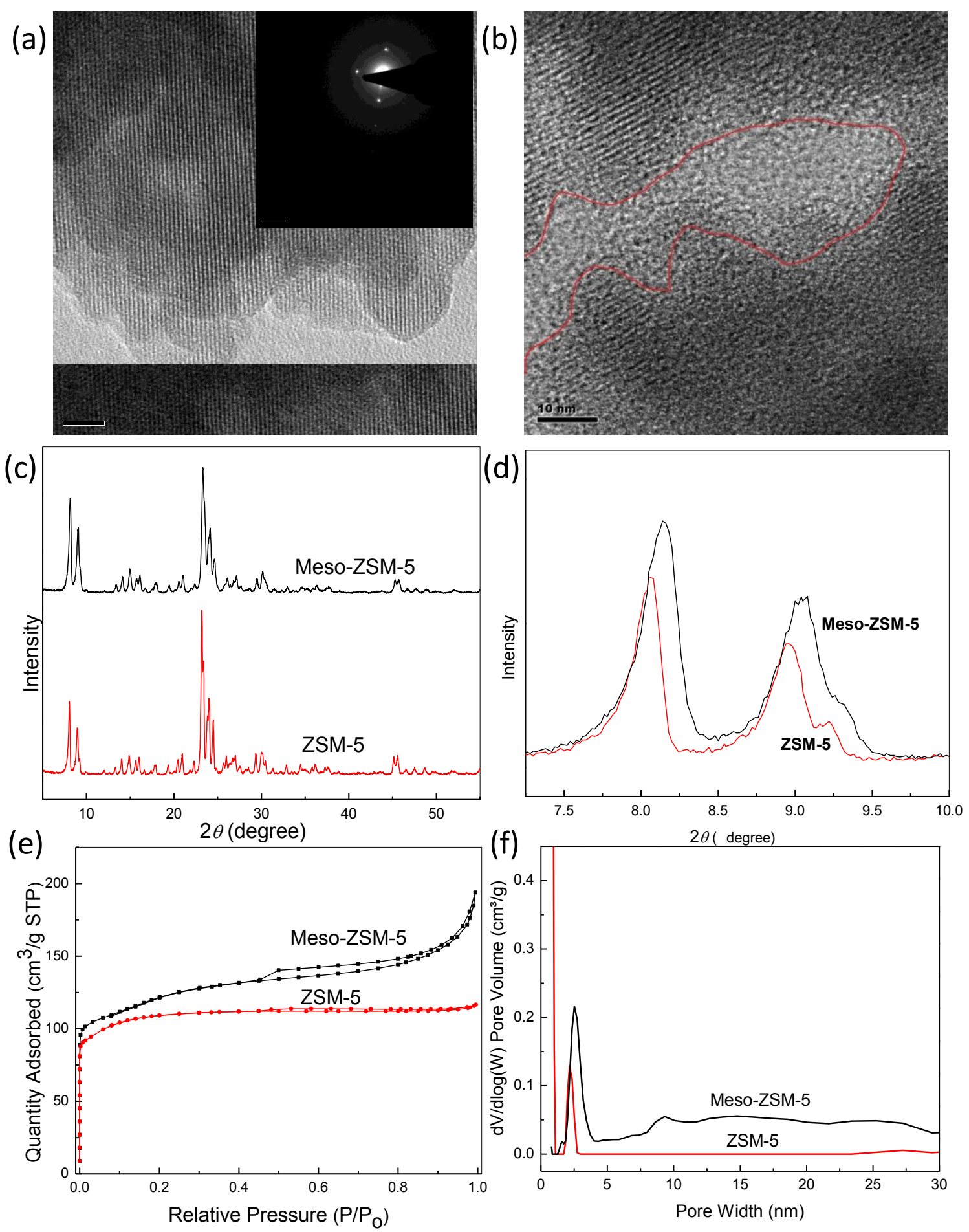

2 Figure 4. (a, b) HRTEM images of Meso-ZSM-5. The inset in (a) is the corresponding electron 3 diffraction pattern of a selected area. (c, d) XRD patterns, (e) $\mathrm{N}_{2}$ sorption isotherms, and (f) the 4 NLDFT pore size distribution plots of Meso-ZSM-5 and conventional ZSM-5. (d) is the 5 amplified XRD pattern of Meso-ZSM-5 between $7-10^{\circ}$ of $2 \theta$. 
(a)

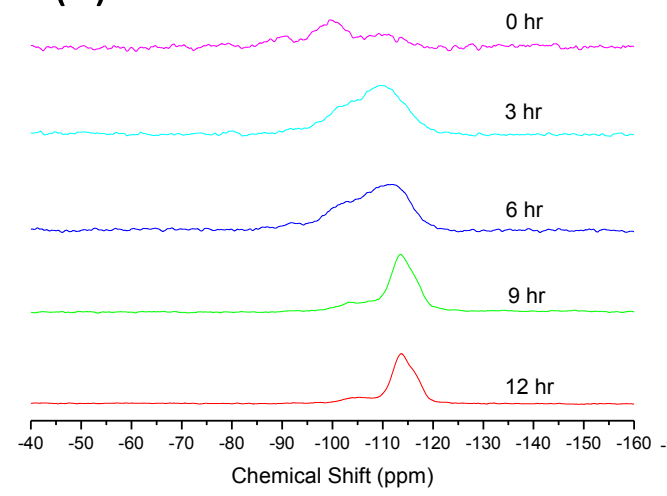

(b)
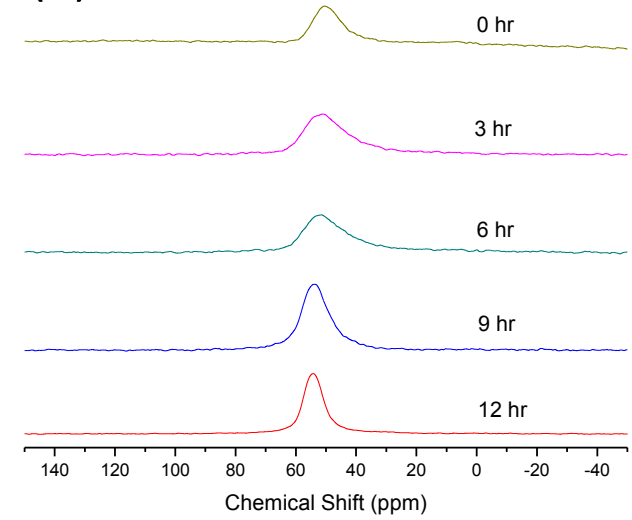

(c)

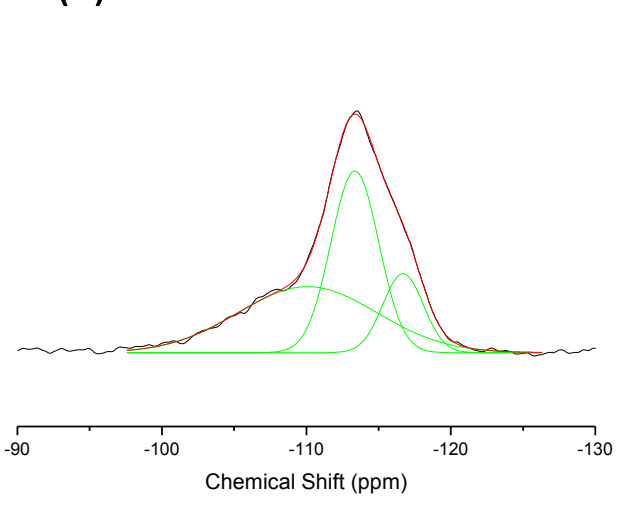

(d)

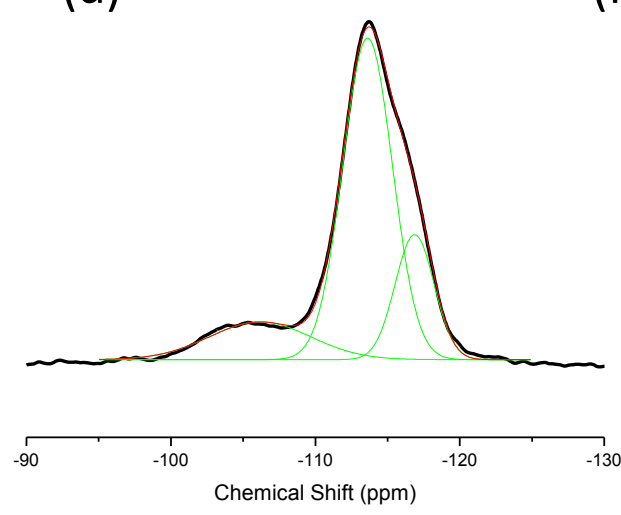

(e)

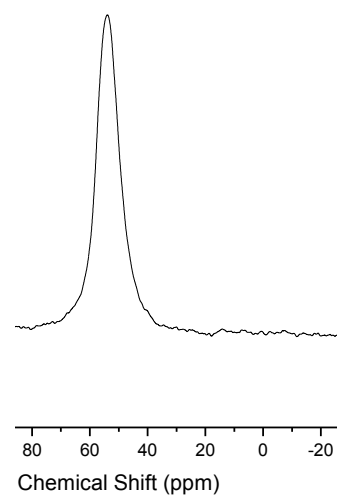

(f)

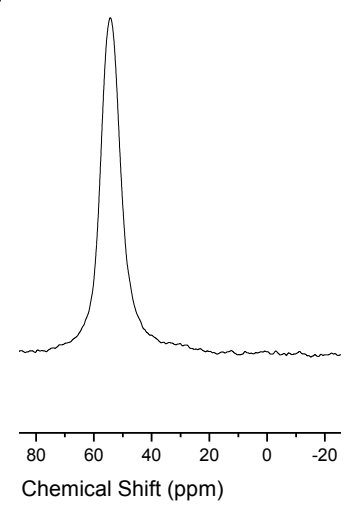

2 Figure 5. Solid-state MAS NMR spectra of Meso-ZSM-5. (a,b) ${ }^{29} \mathrm{Si}$ and ${ }^{27} \mathrm{Al}$ NMR patterns of 3 samples during solid-state crystallization; (c-f) Comparison of ${ }^{29} \mathrm{Si}$ and ${ }^{27} \mathrm{Al}$ NMR patterns of 4 Meso-ZSM-5 (d, f) and microporous ZSM-5 (c,e).

5 The solid-state ${ }^{29} \mathrm{Si}$ and ${ }^{27} \mathrm{Al}$ MAS NMR spectra (Figure 5) were employed to further 6 investigate such framework formation dynamics of Meso-ZSM-5 through local bonding 7 environment changes. ${ }^{29} \mathrm{Si}$ MAS NMR provides information about silicon atoms with different 8 bonding environments in the zeolite framework with silicon atoms connected to silicon,

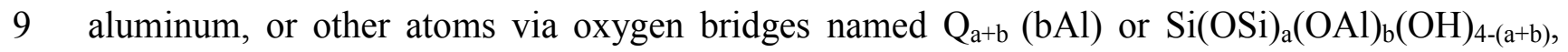
10 where $\mathrm{a}$ and $\mathrm{b}$ are the number of adjacent -OSi and-OAl units attached to $\mathrm{Si}$, respectively. At 11 the begining of the crystallization, the ${ }^{29} \mathrm{Si}$ NMR chemical shift spectra shows one weak but very 12 broad peak between -80 and $-120 \mathrm{ppm}$ due to its amorphous state with silicon atoms connected 13 with multiple hydroxyl group (Figure 5a). With the crystallization ongoing, this peak becomes 14 narrower and its intensity increases, indicating the formaton of Si-O-Si and Si-O-Al bonds. 15 Further extending the crystallization time results in peak split with one centered at $-113 \mathrm{ppm}$ 16 identified as Q4(0Al) species and the other at -105 ppm identified as Q4(1Al) species. ${ }^{27} \mathrm{Al}$ MAS 17 NMR was also collected to reveal the bonding environment around the aluminum atoms in the 
framework (Figure 5b). The spectra feature a chemical shift between 40 and $60 \mathrm{ppm}$ (designated as tetrahedrally coordinated $\mathrm{Al}$ ) and similar peak evolution (i.e., intensity increases, accompanied with a descrease in the full width at half maximum (FWHM)). A well-defined peak is found at a chemcial shift of $54.5 \mathrm{ppm}$ on ${ }^{27} \mathrm{Al}$ MAS NMR of the fully crystallized sample, confirming the isomorphous substitution of $\mathrm{Al}$ in the $\mathrm{SiO}_{4}$ structure. Further comparisons with the ${ }^{29} \mathrm{Si}$ and ${ }^{27} \mathrm{Al}$ spectra with microporous ZSM-5 samples show similar chemical shift pattern, except sharper and better resolved Q4(0Al) and Q4(1Al) peaks in ${ }^{29} \mathrm{Si}$ spectra (Figures $5 \mathrm{c}-5 \mathrm{f}$ ). This further confirms their similar local bonding environement and the successful formation of ZSM-5 framework by this solid-state crystallization process.

\subsection{Discussion on Synthesis Mechanism and Criteria}

In this approach, though most transformations occur in the second solid-state crystallization stage, stage I synthesis is equally critical as it prepares dry, amorphous aluminosilicates nanogels so that precursors could self-assemble into nanoparticle aggregates of appropriate size without initiating crystallization. If these nanogels grow too fast and already start crystallizing in stage I, they would eventually turn into conventional microporous zeolites in later thermal treatment, just like those obtained in traditional hydrothermal synthesis (Figure 6a). This occurs if the original mother solution is too basic (i.e., high $\mathrm{pH}$ ) or the chosen synthesis conditions are very harsh (e.g., high assembly temperature). Besides their amorphous feature, appropriate size is also important for nanogels collected after stage I growth. Nanogels of $50 \mathrm{~nm}$ or less (i.e., maintaining a clear sol in stage I before drying) are appropriate for stage II solidstate crystallization. Unlike most reported mesoporous zeolite synthesis approaches where organic and organosilane mesoporogen as mesotemplate help modulate both the precursor assembly and the hierarchically porous structure construction in the final crystal product, only a structure-directing agent (or so-called microtemplate), TPAOH, is involved in our approach. Besides its main role as governing crystallization of the MFI framework within the building blocks (i.e., amorphous nanogels), TPAOH also creates and maintains a high $\mathrm{pH}$ environment for the dissolution of sodium aluminate. As no substantial liquid water or steam is available for traditional dissolution-addition growth in the solid-state crystallization stage, the dried nanogels obtained from stage I assembly decide their own particle-particle interactions, accumulation, and the later solid crystallization in stage II solid crystallization. The buildup of large ensembles of uniform size from many adjacent nanogels is believed to initiate these transformations. Considering the range of available forces, small nanogels are therefore preferred for particle interactions and attachments. Along with nanogel assembly, such unique supply of needed solvent (i.e., water molecules stored in nanogels) also triggers the nucleation and further crystallization in the confined space of each individual nanogels. With the solid crystallization gradually extending to edges of nanocrystals, neighbouring nanocrystals orient their lattice pattern to each other and merge into a monolithic crystal. Simultaneously, hierarchical interlattice pores are built up between nanocrystals during their periodic piling. Such growth evolution is likely similar to a new aggregative growth model that is found in silicate-1 growth at 
ambient conditions $[42,43]$ or more generally, the particle attachment crystallization mechanism seen in natural mineral formation. [44, 45] But unlike these classical assembly and crystallization in geologic or synthetic environments, nanoparticle powders, not an aqueous suspension of nanoparticles, are involved in our synthesis approach instead. Only water stored in those amorphous nanogels participates and mediates the assembly dynamics and crystallization kinetics. In fact, we found that such format of water and its quantity is the key to successfully build up the shown unique hierarchically porous zeolites with jointed crystal framework in this solid-state crystallization process. If substantial free liquid water or steam was introduced in the solid-state crystallization stage, some nanogels would nucleate earlier than others, consume aluminosilicate precursors from surrounding nanogels, and eventually transform into large piece, single crystal zeolites. As a result, a physically mixture of large, microporous zeolites and aluminosilicate nanoparticles would be obtained (Figure 6b).
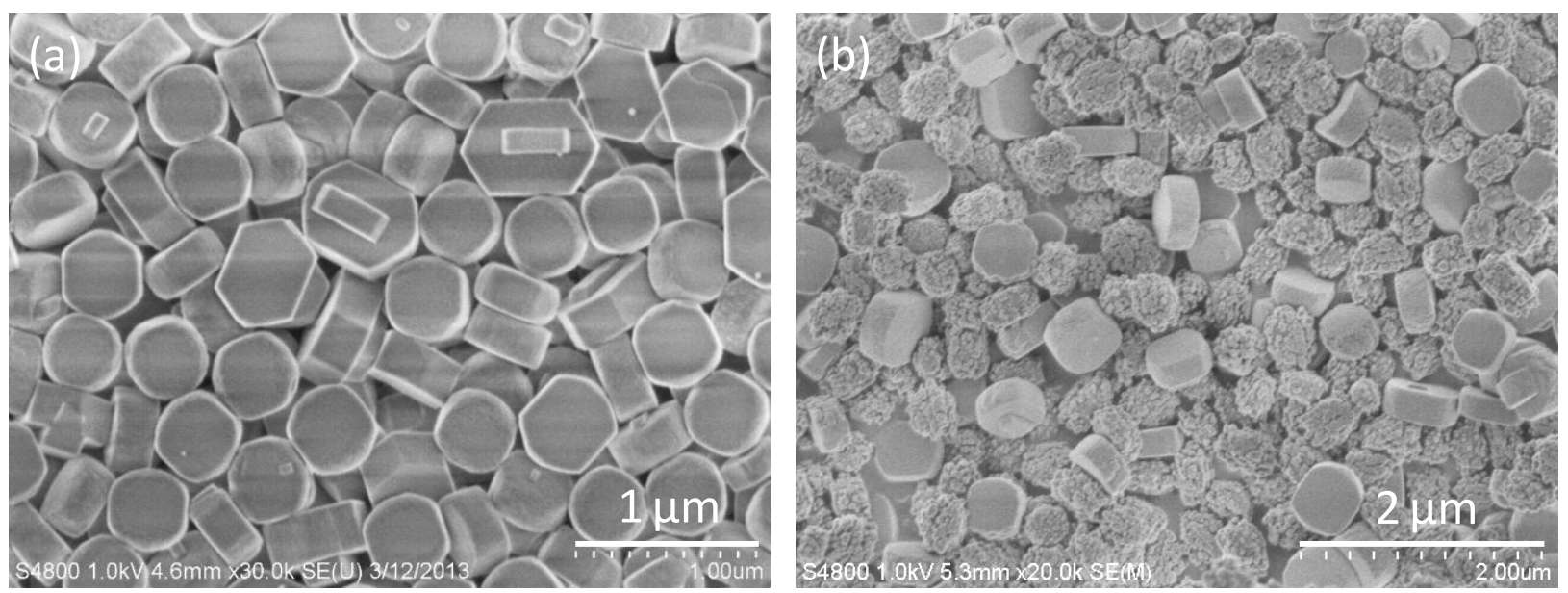

Figure 6. SEM images of samples by preparing (a) aluminosilicate nanogel at high $\mathrm{pH}$ value, followed by stage II solid-state crystallization and (b) aluminosilicate nanogels prepared under appropriate stage I synthesis conditions, followed by traditional hydrothermal treatment.

Due to the critical role of water pre-stored in nanogels to the success of this solid-state crystallization, TGA was used to quantify the water content in nanogel powders obtained from stage I synthesis. Water available for later crystallization comes from two different sources: (1) water encapsulated in nanogels by their thick skin after the overnight evaporation process and (2) water adsorbed from environment as a consequence of significant increase of the total surface area after aluminosilicate gel was ground to powders. To distinguish the amount of water from each source, part of the nanogel sample was kept in an ultra-dry glove box (with water content $<0.1 \mathrm{ppm}$ ) for a week to eliminate the surface adsorbed water. As shown in Figure $7 \mathrm{a}$, the total 
one deeply dried shows only $\sim 10 \%$ loss of weight. This suggests that in solid-state 2 crystallization, water stored in nanogels occupies $\sim 20 \%$ of the total gel weight and is sufficient to 3 fully transform aluminosilicates nanogels to zeolite framework. This is way less than the steam4 assisted crystallization route, in which a water/gel ratio of 10 is commonly used $[38,39])$. In 5 addition, as such stored water is fully utilized in nanogel assembly and transformation, no pressure is built up during synthesis, unlike the traditional hydrothermal or steam-assisted crystallization route in which $>1.0 \mathrm{MPa}$ steam pressure is generated and high-pressure vessels like autoclave are required.

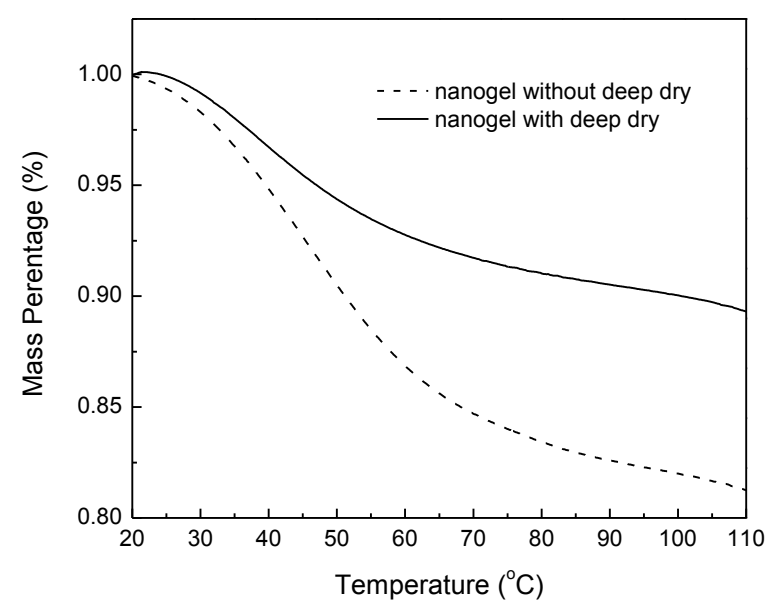

(a)

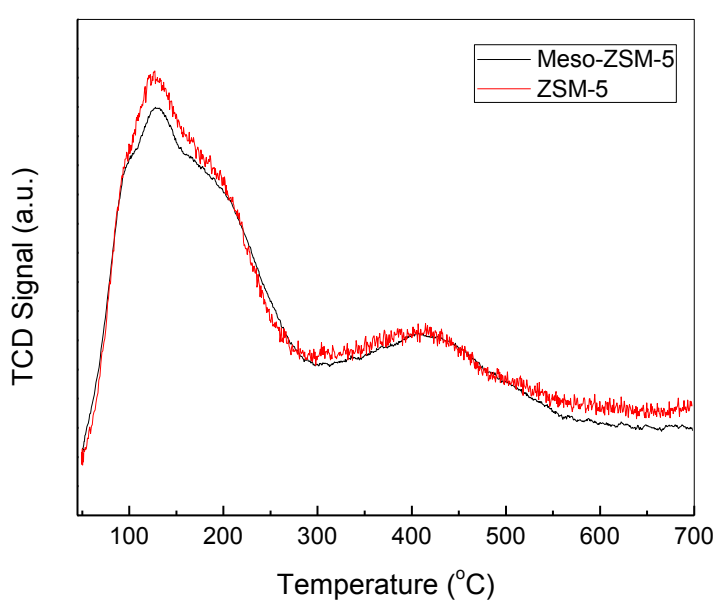

(b)

10 Figure 7. (a) TGA results of nanogels after stage I synthesis with and without further drying; (b) $11 \mathrm{NH}_{3}$-TPD results of Meso-ZSM-5 and ZSM-5 zeolites.

\subsection{Evaluation of Surface Acidity and Stability}

The $\mathrm{NH}_{3}$-TPD analysis was conducted to evaluate the surface acidity of both Meso-ZSM5 and microporous ZSM-5 samples. As depicted in Figure 7b, the two profiles are almost identical, with two separated desorption peaks centered at ca. $140{ }^{\circ} \mathrm{C}$ and ca. $410{ }^{\circ} \mathrm{C}$, which correspond to the weak and strong acid sites of zeolites, respectively. This confirms the similar acidity of Meso-ZSM-5 and microporous ZSM-5, attributed to their similar Si/Al ratios.

Unlike mesopores in physically aggregated nanosized crystals, the hierarchical structure from fused nanocrystals in Meso-ZSM-5 shows excellent stability after being further hydrothermally treated at $150{ }^{\circ} \mathrm{C}$ for $72 \mathrm{~h}$ : the same XRD and NMR patterns and peak intensity are preserved (Figures 8a, 8c \& 8d), so do their size, morphology (Figure 8b), and the later catalytic activity (Figure 9b). These results indicate that the monolithic Meso-ZSM-5 synthesized by our approach has good hydrothermal stability. It also proves that the solid-state crystallization process is completed after the 12-hour calcination and the produced Meso-ZSM-5 zeolites indeed 
1 reach their stable crystalline structure, not just some intermediates collected from the middle of a

2 slow crystallization process.
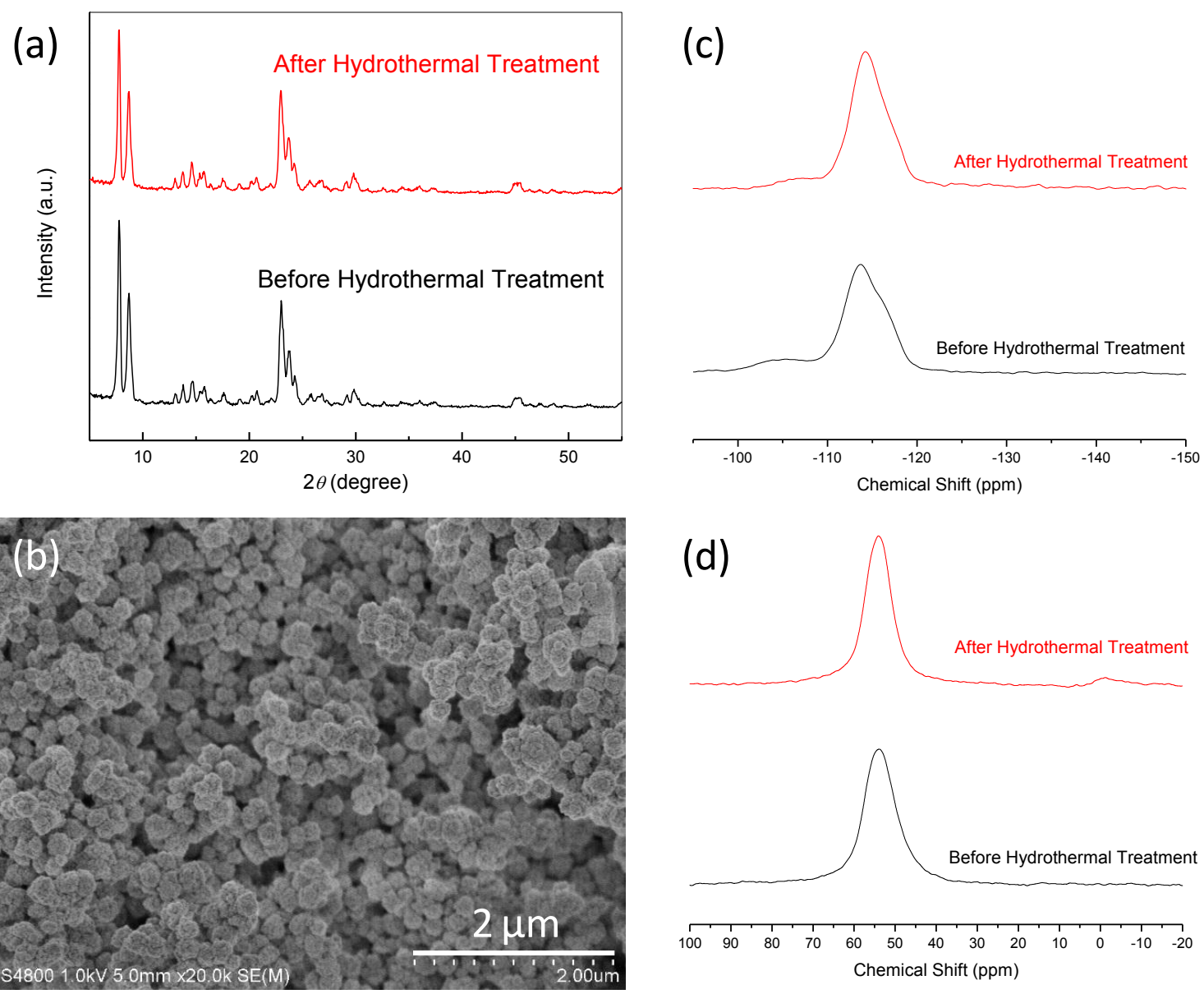

Figure 8. Hydrothermal stability tests. (a) XRD patterns and (b) SEM image of Meso-ZSM-5 5 after additional hydrothermal treatment; (c) ${ }^{29} \mathrm{Si}$ and (d) ${ }^{27}$ Al MAS NMR patterns of Meso-ZSM65 before and after hydrothermal treatment.

\section{$7 \quad 3.4$ Evaluation of Catalytic Performance}

Although having similar overall acidity, the unique textural features of Meso-ZSM-5 9 zeolites synthesized by our approach are expected to promote the utilization of active sites and 10 diffusion of zeolites with bulky reactants and/or products from two different aspects: (i) its 11 nanocrystal building units help expose more accessible active sites of zeolites to bulky 12 molecules; (ii) the connected mesoscale pathways among these jointed nanocrystals reduce the 13 diffusion barriers for these large reactant molecules to reach them and for possible bulky product 14 molecules diffuse out to avoid pore blocking. 
Such catalytic performance improvement of Meso-ZSM-5 was first evaluated with the

3 Friedel-Crafts alkylation of benzene with benzyl alcohol, a typical diffusion-constrained reaction

4 with both bulky reactants and products (Figure 9a). As shown in Figure 9b, Meso-ZSM-5 shows

5 a much higher catalytic conversion of benzyl alcohol than the conventional ZSM-5 after a 6-hour

6 reaction at $80{ }^{\circ} \mathrm{C}$ ( $71 \%$ for Meso-ZSM- 5 versus $11 \%$ for ZSM-5). Considering their similar Si/Al

7 ratio $(\mathrm{Si} / \mathrm{Al}=33)$ and acidity (Figure $7 \mathrm{~b}$ ), this suggests that the outstanding catalytic activity of

8 Meso-ZSM-5 is mainly attributed to its mesoporous structure. The connected mesoscale

9 pathways allow bulky reactants (e.g., benzyl alcohol) and products (e.g., diphenylmethane) to

10 transport to the active sites easier. Such unique hierarchical configuration also provides more 11 accessible active sites on the jointed nanocrystals. Unlike mesopores in physically aggregated

12 nanosized crystals, the hierarchical structure from fused nanocrystals in Meso-ZSM-5 shows 13 excellent stability after being further hydrothermally treated: the same catalytic activity in 14 Friedel-Crafts alkylation (Figure 9b).

(a)

(b)
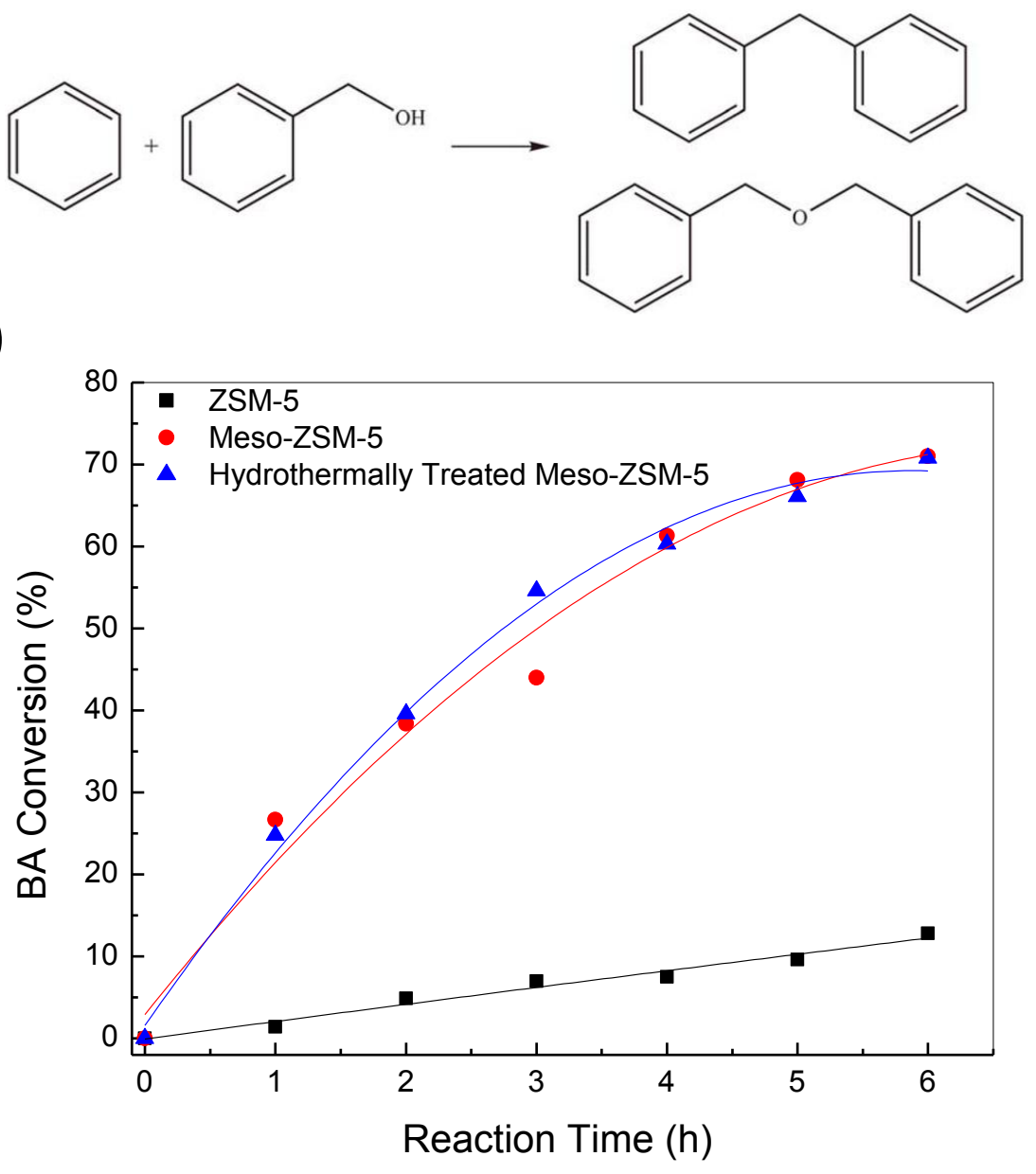

Figure 9. (a) Schematics of Friedel-Crafts alkylation of benzene with benzyl alcohol and (b)

17 benzyl alcohol conversion over Meso-ZSM-5 and conventional ZSM-5. 
Considering the large quantity demand of zeolites in biomass conversion processes and the environment-friendly synthesis advantage of our Meso-ZSM-5, the catalytic performance of Meso-ZSM-5 was further checked in lignin depolymerization for its effective promotions for the transport of giant reactants and/or products. As the second most abundant natural polymer, lignin has long been a high-volume major byproduct and environmental hazard of the paper and pulp industry. Depolymerization of lignin recently drew great attentions, not just for its environmental benefits on eliminating such major pollution waste, but also for its promising potentials in producing high-value aromatics as renewable chemicals and fuels.[46] However, cracking lignin fragments to release the rich phenol-type aromatics is not trivial, considering the difficulty on effective cleavage of the many $\mathrm{C}-\mathrm{O}-\mathrm{C}$ and $\mathrm{C}-\mathrm{C}$ linkages in its molecular structure and diffusion barriers to its truly gigantic fragments. Processes like hydrolysis, oxidation, and reduction of lignin have been investigated with the help of noble metal and/or hydrotreating catalysts.[47-49] Among these processes, ethanolysis under supercritical conditions (Figure 10a) is favourable with its high conversion and no char formation benefits. The ethanolysis of Kraft lignin was carried out in a batch reactor after purging with $\mathrm{N}_{2}$ under operation conditions $\mathrm{s}$ to some other research work (i.e., at $280{ }^{\circ} \mathrm{C}$ under a pressure of $8 \mathrm{MPa}$ for $6 \mathrm{~h}$. [50]). Similar to benzylation reactions, Meso-ZSM-5 exhibited a higher conversion of lignin (72.5\%), when compared to that of ZSM-5 (62.6\%) and no tar or char was found. A total of 22 molecules with a mass weight of more than $1.0 \%$ of all products were detected by gas chromatography-mass spectrometry (GCMS), as shown in Figure 10b. Some products eluted early in the GC-MS spectrum, particularly the three different types of short-chain ether, are mainly derivate of ethanol reforming reactions at the presence of zeolites. This is verified when comparing the GC-MS spectrum of lignin ethanolysis products with that from reactions involving only ethanol and zeolites at the same conditions (Figure 10b). Mass spectrum peaks of other 17 products including different types of alcohol, acetal, and aromatics appeared only when lignin was added. The early eluted ones in lignin depolymerization samples, with short chains of $\mathrm{C}_{4}-\mathrm{C}_{6}$, such as butanol, acetate, and acetal, show similarly peak intensity in the GC-MS spectrums for ethanolysis products using MesoZSM-5 and microporous ZSM-5. But signals of the later eluted compounds of $\mathrm{C}_{8}-\mathrm{C}_{11}$, most as aromatics, increases greatly for samples depolymerized by Meso-ZSM-5 than that using microporous ZSM-5 (Figures 10b-10d). The high-yield of overall aromatics (49.3\% for MesoZSM-5 versus $32.6 \%$ for ZSM-5) with more diversified individual compounds suggests deeper breakdown of lignin fragments over Meso-ZSM-5 (Figure 10d). More small, high-valued aromatics, especially desired phenols such as guaiacol $(\sim 20 \%)$ and alkane substituted guaiacols such as ethylguaiacol and methylguaiacol ( 15\%), have obviously high yield over Meso-ZSM-5 catalyst, as shown in Figures $10 \mathrm{~b}$ and $10 \mathrm{~d}$. As comparison, the major aromatic product in ethanolysis over traditional microporous ZSM-5 is 1,2-Dimethoxy-4-(1-methoxyethenyl) benzene $(\sim 25 \%)$, a relatively large intermediate aromatic fragment, together with quite limited phenol-type, small fragments $(\sim 6.2 \%)$. Similar to what occurs in Friedel-Crafts alkylation, the 
1 exposed active sites on their nanosized zeolite building units and the mesoscale connecting 2 channels to them in the monolithic crystal. Large fragments of lignin such as 1,2-Dimethoxy-43 (1-methoxyethenyl)benzene can readily reach the active sites of zeolites for further cracking into 4 smaller fragments (e.g., phenols) before leaving the catalyst surface. Although the reactions 5 occurred in supercritical ethanol, Meso-ZSM-5 zeolites still kept their original size and 6 morphology with no sign of crystal broken after the 6-hour high-temperature, high pressure 7 reaction (supplemental Figures $2 \mathrm{a} \& \mathrm{~b}$ ). This evidence again endorses the superior stability of 8 Meso-ZSM-5 obtained by our template-free assembly and solid-state crystallization approach. It 9 also further supports the conclusion that the edges of nanocrystals in Meso-ZSM-5 are indeed 10 fused together as single monolithic crystal, rather than some physical aggregates of many 11 nanocrystals of zeolites.

12
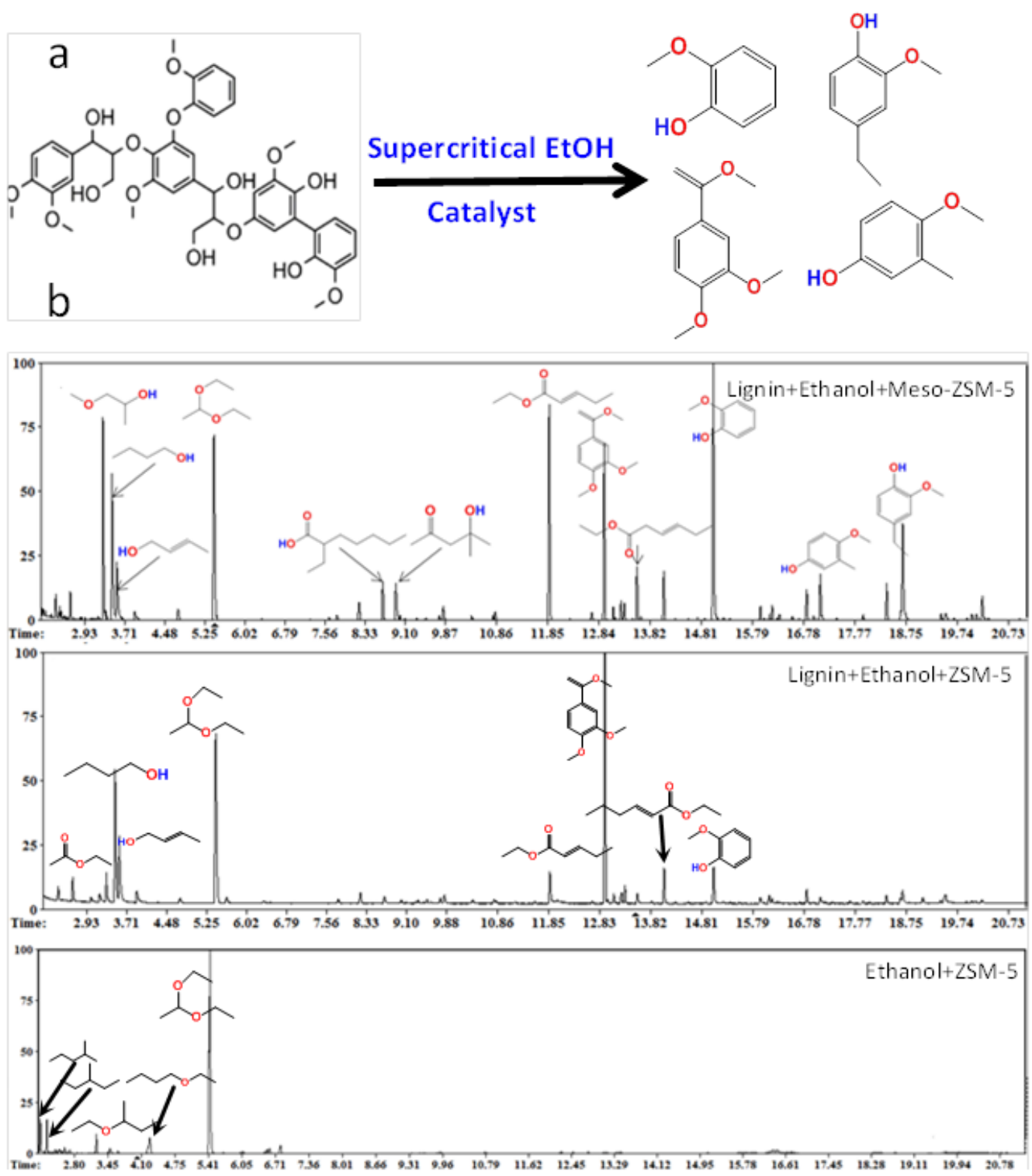

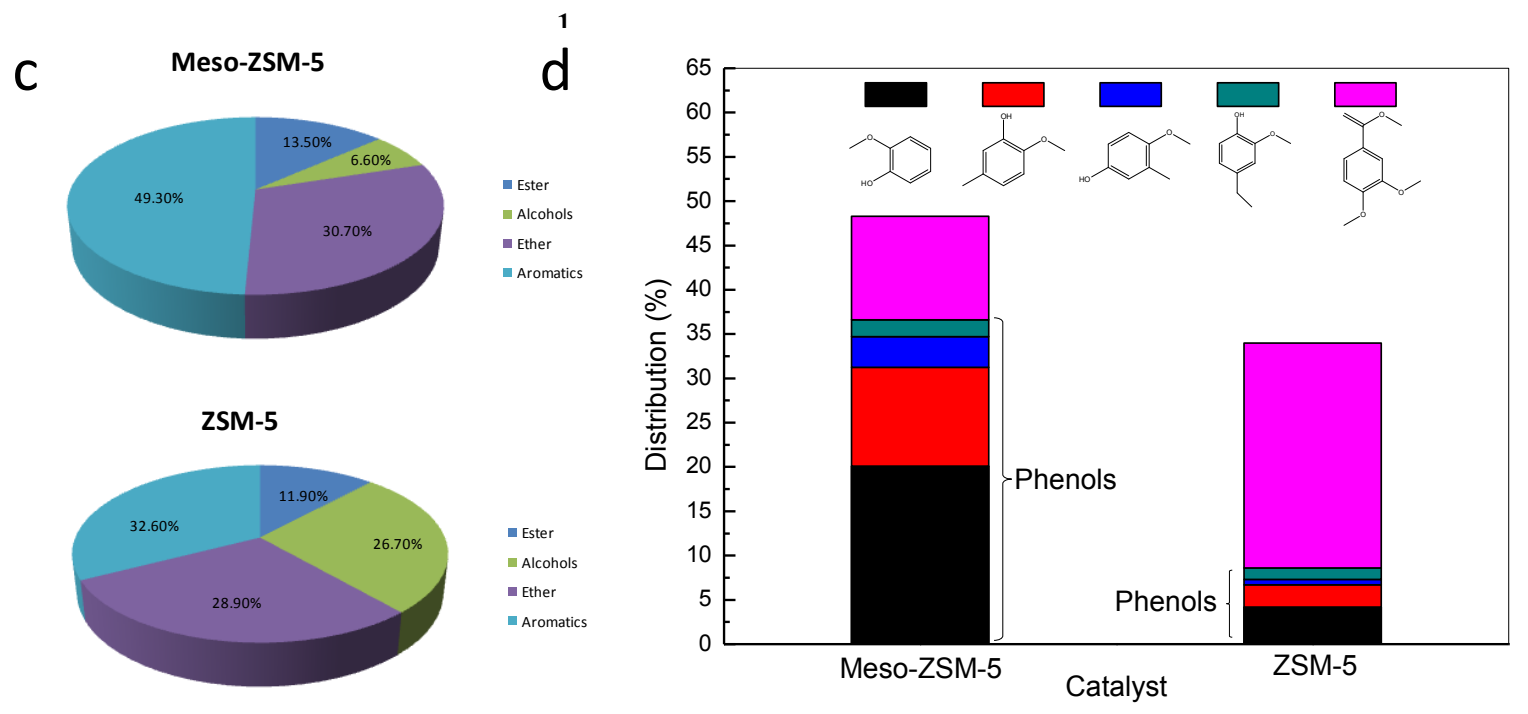

9 Figure 10. (a) Schematics of lignin ethanolysis, (b) GC-MS spectrums of lignin ethanolysis over 10 Meso-ZSM-5, conventional ZSM-5, and only ethanol and zeolites, and (c-d) the product 11 distribution (c: overal; d: among aromatics) in lignin ethanolysis over Meso-ZSM-5 and 12 conventional ZSM-5.

\subsubsection{Catalytic Performance in Hydrogeneation of Naphthelene}

Deep hydrogenation of aromatics is one of the most important unit operations in modern oil-refinery and coal liquefaction industries. [51-53]. The produced cycloalkane can significantly increase the cetane number $(\mathrm{CN})$ of fuel, improve its combustion performane, and enhance its thermal stability even in some critical environments (e.g., for jet fuel) [53]. Because of its exothermic reaction feature, aromatics hydrogenation is thermodynamically favored at low temperature, for which noble metal supported catalyst is desired. Some recent studies found that when supported on acidic materials such as USY or Beta zeolites, noble metal catalyst such as platinum (Pt) showed much improved catalytic activity and sulfur tolerance in deep hydrogenation of aromatics. [54-56] However, the sole microporosity of these zeolites often makes these reactions less effective when bulky aromatic hydrocarbons such as naphthelene (a major compound of light cycle oil or coal tar) are involved due to the significant mass transfer limitation [57]. Here we investigate the catalytic performance of this new Pt/Meso-ZSM-5 catalyst in naphthalene hydrogenation. The reaction was performed in a batch reactor at $200^{\circ} \mathrm{C}$ with a hydrogen pressure of 7.5 MPa. Figure 11a shows the reaction network of naphthalene hydrogenation, with main compounds as partially hydrogenated tetralin and fully saturated cisor trans-decalin. As shown in Figure 11b, the reaction rate of naphthalene is much faster over Pt/Meso-ZSM-5 catalyst than that over Pt/ZSM-5, with the conversion of naphthalene reaches to $100 \%$ within 3 hours. In contrast, only $\sim 80 \%$ of naphthalene is consumed over Pt/ZSM-5 catalyst 
1 at the end of a 5-hour reaction time. As demonstrated by other researchers, the hydrogenation of 2 naphthalene to tetralin is much easier than the further hydrogenation of tetralin to decalin, with 3 the reaction rate of the former about 30 times higher than the latter. [56, 58]. Hence decalin 4 selectivity is often used as criterion to evaluate the performance of catalyst in naphthalene 5 hydrogenation. From Figure 11c, no decalin is detected in the hydrogenation product over $6 \mathrm{Pt} / \mathrm{ZSM}-5$. The production of tetralin is also delayed for about an hour when enough naphthalene 7 is converted and then goes up. This confirms the poor deep hydrogenation activity of Pt/ZSM-5 8 at such low hydrogenation temperature $\left(200^{\circ} \mathrm{C}\right)$. But over Pt/Meso-ZSM-5, thanks to the quick 9 consumption of naphathalene, both tetralin and decalin present in the hydrogenation product 10 even at the early stage. The decalin selectivity continue going up when more naphthalene is 11 converted and its selectivity exceeds that of tetralin after one hour. Among all decalin products, 12 nearly equal quantity of trans- and cis-decalin presents.

(a)

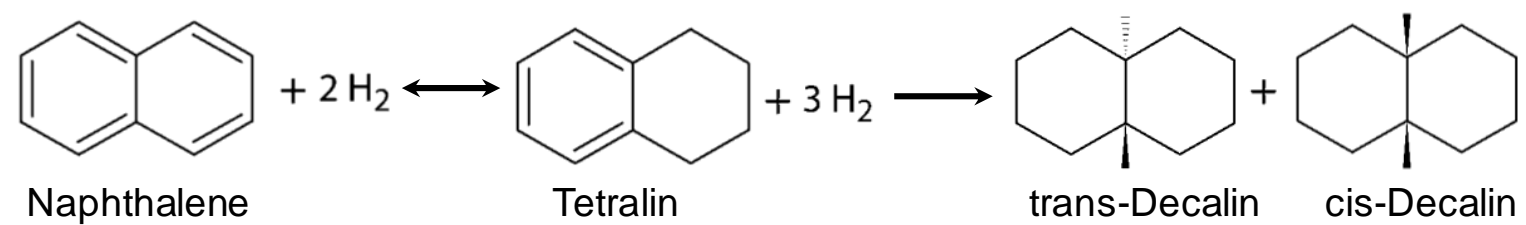

(b)

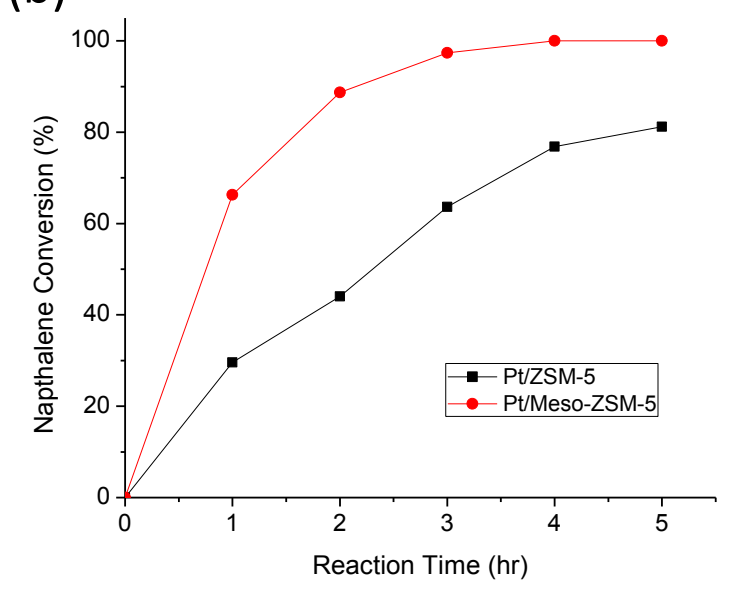

(c)

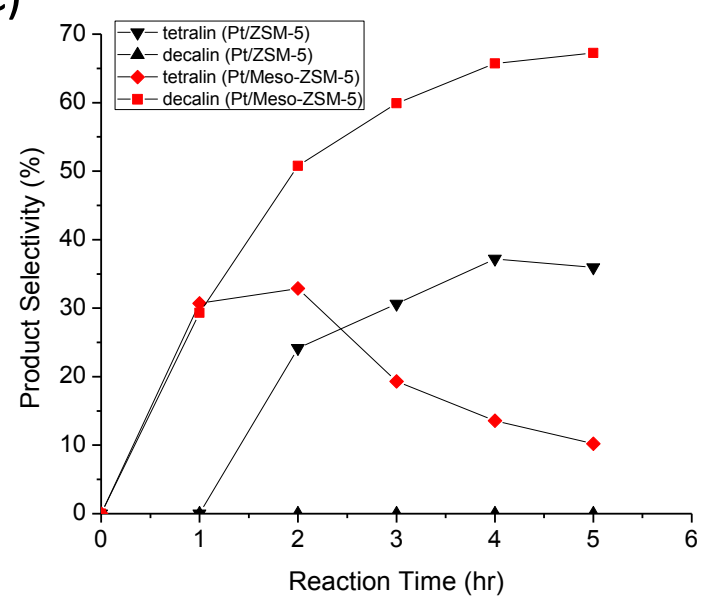

15 Figure 11. (a) Schematics of hydrogenation of naphthelene, (b) kinetics of naphthelene 16 conversion and (c) the product selectivity of in naphthelen hydrogenation over Pt/Meso-ZSM-5 17 and Pt/conventional ZSM-5. 
Similar to the other two ZSM-5 catalyzed reactions involved bulky molecules, the improvement of such naphthalene hydrogenation performance over Pt/Meso-ZSM-5 is attributed to its unique mesoporous/microporous bimodal porous structure and strong acidity. Compounds involved in naphthalene hydrogenation have their molecular sizes between 0.50 and $0.71 \mathrm{~nm}$, which could transport easily in mesoporoes of Meso-ZSM-5, while face significant resistance inside the 10-member ring of microporous ZSM-5. On Pt/ZSM-5, poorer hydrogenation capacity is attributed to such diffusion limitation of naphthalene and tetralin in their micropores. Such a result is in accordance with a previous report by Pawelec et al. [56]. In contrast, our staged hierarchical porosity (i.e., connected macropores, mesopores, and micrpores) of Meso-ZSM-5 allows Pt particles to reach deep to the more exposed surface of zeolites during the wet impregnation. More electron-deficient Pt active centers attributed to effective hydrogenation could also be formed and become accessible in Pt/Meso-ZSM-5 during the partial electron transfer from Pt particles to acidic sites of zeolites, unlike in Pt/ZSM-5, some Pt active centers and the secondly spillover based hydrogenation pathway cannot be reached. The spillover hydrogen coming from connected microporores in Pt/Meso-ZSM-5 could further promote the hydrogenation of tetralin adsorbed on the acidic sites of zeolites to the saturated decalin before leaving those active sites. Based on these benefits (enhanced reactant/product diffusion and promoted hydrogenation pathways), it is not surprise to achieve much higher catalytic activity of naphthalene hydrogenation and selectivity to saturated decalin over Pt/Meso-ZSM-5 than that over Pt/ZSM-5. This not only proves the excellent deep hydrogenation performance of this new catalyst, but the high yield of decalin compounds (the saturated hydrocarbons) may also bring great profit to the fuel business of the oil-refinery and coal liquefaction industries from the perspective of producing high $\mathrm{CN}$ fuel like diesel ( $\mathrm{CN}$ for naphthalene is 1 , tetralin is 10 , and decalin is 36) and fuel with superior thermal stability at extreme conditions like jet fuel.

\subsection{Zeolite Processing Advantage of this Solid-State Crystallization Process}

This new synthesis approach provides not only hierarchical zeolites of unique textural features (i.e., jointed nanocrystals with inter-crystalline mesovoids) and enhanced catalytic performance in multiple important operations in modern oil-refinery and coal liquefaction industries, but also solutions to some severe material, economics, and environmental issues associated with traditional hydrothermal zeolite production routes. First, our synthesis involves only solid crystallization. As no liquid is loaded and no pressure is built up during crystallization, the crystallization vessel could be fully loaded, which will significantly increase the zeolites yield. Moreover, as the crystallization is carried out at atmospheric pressure, any vessels that are capable of tight seal at elevated temperature and resistant to basic liquid can be used, unlike traditional hydrothermal or steam-assisted crystallization, high-pressure vessels like autoclave is mandatory. This will significantly save cost on the synthesis equipment as well as its operation. In addition, this largely reduces the liquid pollution generated in traditional hydrothermal zeolite synthesis, in which a large percentage of alkali, silicates, and aluminates are left in the postsynthesis solution. These unused chemicals not only lower the overall zeolite yield, but also 
generate a large amount of waste liquid. With their recovery difficult and costly, this causes severe environmental pollution in zeolite industry. In contrast, our approach has all silicates and aluminates integrated in nanogels during stage I synthesis and carries out crystallization with only solid powders. This even eliminates the requirement for small amount of water that is critical in a different solvent-free synthesis route. [36] It helps increase zeolite yield, and more importantly, produces almost no liquid waste to the environment. Second, neither hard mesotemplate nor special soft meso-template materials are involved in our approach. This avoids aforementioned challenges for the common carbon or $\mathrm{CaCO}_{3}$ hard meso-template (i.e., incompatibility of template and precursors) as well as cationic polymer or amphiphilic organosilane based soft meso-templates (i.e., synthesis difficulty for template macromolecule, their availability, and cost). It not only saves significantly the production cost, but also simplifies the synthesis procedures, even when comparing with the post-synthesis treatment methods. Although a structure directing agent (or so-called organic microtemplate), TPAOH, is used, they are encapsulated in nanogels and later produced zeolites during synthesis and are removed during zeolite calcination. Its air pollution concerns from the volatile toxic compounds released from TPAOH calcinations could be further minimized by drastically reducing its dosage during zeolite synthesis, which has been proved feasible for ZSM-5 by other researchers using a lowtemperature hydrothermal synthesis or a steam-assisted crystallization process [38, 59]. Nevertheless, the advantages of this solid-state crystallization process could help promote the profit of hierarchical zeolites production and its environment-friendly synthesis.

\section{4. Conclusions}

22 In summary, hierarchical zeolites ZSM-5 is successfully produced in a new two-stage synthesis 23 process with meso-template free assembly and solid-state crystallization. The resulting mesoporous zeolites show excellent hydrothermal stability and superior catalytic performance in reactions like Friedel-Crafts alkylations, lignin depolymerization in supercritical ethanol, and deep hydrogenation of naphthalene, all involve bulky aromatic molecules. Its unique mesotemplate free synthesis and solid crystallization conditions largely simplify the synthesis routes of zeolites, reduce its production cost, and avoid common liquid pollution issues in zeolite industry. Its superior catalytic performance and economically favourable synthesis route may

30 stimulate further exploration interest for its large-scale production and wide effectiveness to a

31 variety of applications requiring hierarchical zeolites.

\section{Acknowledgments}

33 This work was supported by National Science Foundation under Grant [1130468] and Louisiana

34 Harrelson Family Professorship. 
[1] A. Corma, From microporous to mesoporous molecular sieve materials and their use in catalysis. Chem. Rev. 97 (1997) 2373-2420.

[2] M. E. Davis, Ordered porous materials for emerging applications. Nature 417 (2002) 813821.

[3] A. Corma, State of the art and future challenges of zeolites as catalysts. J. Catal. 216 (2003) 298-312.

[4] Y. Y. Sun, R. Prins, Hydrodesulfurization of 4, 6-Dimethyldibenzothiophene over Noble Metals Supported on Mesoporous Zeolites. Angew. Chem. Int. Ed. 47 (2008) 8478-8481.

[5] M. Bejblova, D. Prochazkova, J. Čejka, Acylation reactions over zeolites and mesoporous catalysts. ChemSusChem 2 (2009) 486-499.

[6] Y. N. Li, S. L. Liu, Z. K. Zhang, S. J. Me, X. X. Zhu, L. Y. Xu, Aromatization and isomerization of 1-hexene over alkali-treated HZSM-5 zeolites: Improved reaction stability. Appl. Catal. A 338 (2008) 100-113.

[7] Y. Wang, Y. Fang, T. He, H. Hu, J. Wu, Hydrodeoxygenation of dibenzofuran over noble metal supported on mesoporous zeolite. Catal. Commun. 12 (2011) 1201-1205.

[8] T. He, Y. Wang, P. Miao, J. Li, J. Wu, Y. Fang, Hydrogenation of naphthalene over noble metal supported on mesoporous zeolite in the absence and presence of sulfur. Fuel 106 (2013) 365-371.

[9] Y. Wang, T. He, K. Liu, J. Wu, Y. Fang, From biomass to advanced bio-fuel by catalytic pyrolysis/hydro-processing: hydrodeoxygenation of bio-oil derived from biomass catalytic pyrolysis. Bioresour. Technol. 108 (2012) 280-284.

[10] J. Jiang, J. Yu, A. Corma, Extra-Large-Pore Zeolites: Bridging the Gap between Micro and Mesoporous Structures. Angew. Chem. Int. Ed. 49 (2010) 3120-3145.

[11] L. Chen, X. Li, J.C. Rooke, Y. Zhang, X. Yang, Y. Tang, F. Xiao, B. Su, Hierarchically structured zeolites: synthesis, mass transport properties and applications. J. Mater. Chem. 22 (2012) 17381-17403.

[12] Y. Wang, J. Wu, S. Wang, Hydrodeoxygenation of bio-oil over Pt-based supported catalysts: importance of mesopores and acidity of the support to compounds with different oxygen contents. RSC Adv. 3 (2013) 12635-12640.

[13] C. Herrmann, J. Haas, F. Fetting, Effect of the crystal size on the activity of ZSM-5 catalysts in various reactions. Appl. Catal. 35 (1987) 299-310.

[14] Z. Wang, C. Li, H.J. Cho, S. Kung, M.A. Snyder, W. Fan, Direct, single-step synthesis of hierarchical zeolites without secondary templating. J. Mater. Chem. A 3 (2015) 1298-1305.

[15] H. Wang, Z. Wang, L. Huang, A. Mitra, B. Holmberg, Y. Yan, High-surface-area zeolitic silica with mesoporosity. J. Mater. Chem. 11 (2001) 2307-2310. 
1 [16] P. Behrens, Mesoporous inorganic solids. Adv. Mater. 5 (1993) 127-132.

2 [17] T. Wakihara, K. Sato, S. Inagaki, J. Tatami, K. Komeya, T. Meguro, Y. Kubota, Fabrication of fine zeolite with improved catalytic properties by bead milling and alkali treatment. ACS Applied Materials \& Interfaces 2 (2010) 2715-2718.

[18] Y. Wang, K. Liu, T. He, J. Wu, Y. Fang, Zeolite with trimodal porosity by desilication of zeolite nanocrystals aggregate. J. Solid State Chem. 194 (2012) 416-421.

[19] C. Ju, Y. Wang, Y. Huang, Y. Fang, Design of mesoporous KA zeolite supported sulfurtolerant noble metal catalyst for naphthalene hydrogenation. Fuel 154 (2015) 80-87.

[20] J. Jiang, J. L. Jorda, J. Yu, L. A. Baumes, E. Mugnaioli, M. J. Diaz-Cabanas, U. Kolb, A. Corma, Synthesis and structure determination of the hierarchical meso-microporous zeolite ITQ-43. Science 333 (2011) 1131-1134.

[21] Z. Yang, Y. Xia, R. Mokaya. Zeolite ZSM-5 with unique supermicropores synthesized using mesoporous carbon as a template. Adv. Mater. 16 (2004) 727-732.

[22] J.E. Schmidt, D. Xie, M.E. Davis, Synthesis of the RTH-type layer: the first small-pore, two dimensional layered zeolite precursor. Chem. Sci. 6 (2015) 5955-5963.

[23] W. Fan, M. A. Snyder, S. Kumar, P.-S. Lee, W. C. Yoo, A. V. McCormick, R. L. Penn, A. Stein, M. Tsapatsis, Hierarchical Nanofabrication of Microporous Crystals with Ordered Mesoporosity. Nat. Mater. 7 (2008) 984-991.

[24] H. Wang, T. J. Pinnavaia, MFI zeolite with small and uniform intracrystal mesopores. Angew. Chem. Int. Ed. 45 (2006) 7603-7606.

[25] S. Du, F. Li, Q. Sun, N. Wang, M. Jia, J. Yu, A green surfactant-assisted synthesis of hierarchical TS-1 zeolites with excellent catalytic properties for oxidative desulfurization. Chem. Commun. 52 (2016) 3368-3371.

[26] M. Choi, D.-H. Lee, K. Na, B.-W. Yu, R. Ryoo, High Catalytic Activity of Palladium (II)-Exchanged Mesoporous Sodalite and NaA Zeolite for Bulky Aryl Coupling Reactions: Reusability under Aerobic Conditions. Angew. Chem. Int. Ed. 48 (2009) 3673-3676.

[27] L. Emdadi, Y. WU, G. Zhu, C.-C. Chang, W. Fan, T. Pham, R. F. Lobo, D. Liu, Dual template synthesis of meso-and microporous MFI zeolite nanosheet assemblies with tailored activity in catalytic reactions. Chem. Mater. 26 (2014) 1345-1355.

[28] B. Li, Z. Hu, B.o Kong, J. Wang, W. Li, Z. Sun, X. Qian, Y. Yang, W. Shen, H. Xu, D. Zhao, Hierarchically tetramodal-porous zeolite ZSM-5 monoliths with template-freederived intracrystalline mesopores. Chem. Sci. 5 (2014) 1565-1573.

[29] M. Choi, R. Srivastava, R. Ryoo, Organosilane surfactant-directed synthesis of mesoporous aluminophosphates constructed with crystalline microporous frameworks. Chem. Commun. 42 (2006) 4380-4382. 
1 [30] K. Na, M. Choi, W. Park, Y. Sakamoto, O. Terasaki, R. Ryoo, Pillared MFI Zeolite

[31] G. A. Ozin, A. Kuperman, A. Stein, Advanced zeolite materials science. Adv. Mater. 1 (1989) 69-86.

[32] A. Sakthivel, S. Huang, W. Chen, Z. Lan, K. Chen, T. Kim, R. Ryoo, A. S. Chiang, S. Liu, Replication of mesoporous aluminosilicate molecular sieves (RMMs) with zeolite framework from mesoporous carbons (CMKs). Chem. Mater. 16 (2004) 3168-3175.

[33] D. P. Serrano, J. M. Escola, P. Pizarro, Synthesis strategies in the search for hierarchical zeolites. Chem. Soc. Rev. 42 (2013) 4004-4035.

[34] D. Verboekend, J. Pérez-Ramírez, Towards a sustainable manufacture of hierarchical zeolites. ChemSusChem 7 (2014) 753-764.

[35] R. Xu, W. Pang, J. Yu, Q. Huo, J. Chen, in Chemistry of zeolites and related porous materials: synthesis and structure, John Wiley \& Sons (Asia) Pte Ltd, 2007, pp. 117-189.

[36] L. Ren, Q. Wu, C. Yang, L. Zhu, C. Li, P. Zhang, H. Zhang, X. Meng, F. Xiao, Solventfree synthesis of zeolites from solid raw materials. J. Am. Chem. Soc. 134 (2012) 1517315176.

[37] G. W. Huber, A. Corma, Syneergies between bio- and oil refineries for the production of fuels from biomass, Angew. Chem. Int. Ed. 46 (2007) 7184-7201.

[38] M. Rilyanti, R. R. Mukti, G. T. M. Kadja, M. O. Ogura, H. Nur, E.-P. Ng, Ismunandar, On the drastic reduction of organic structure directing agent in the steam-assisted crystalliation of zeolite with hierarchical porosity, Microporous and Mesoporous Materials, 230 (2016) 30-38.

[39] Y. Zhang, K. Zhu, X. Zhou, W. Yuan, Synthesis of hierarchically porous ZSM-5 zeolites by steam-assisted crystallization of dry gels silanized with short-chain organosilanes, New Journal of Chemistry, 38 (2014) 5808-5816.

[40] J. Garcia-Martinez, C. Xiao, K. A. Cychosz, K. Li, W. Wan, X. Zou, M. Thommes, Evidence of intracrystalline mesostructured porosity in zeolites by advanced gas sorption, electron tomography and rotation electron diffraction, ChemCatChem 6 (2014) 3110-3115.

[41] M. Thommes, K. Kaneko, A.V. Neimark, J. P. Oliver, F. Rodriguez-Reinoso, J. Rouquerol, K. S.W. Sing, Physiorption of gas, with special reference to the evaluation of surface area and pore size distribution (IUPAC Technical Report), Pure Appl. Chem. 87 (2015) 10511069.

[42] T. M. Davis, T. O. Drews, H. Ramanan, C. He, J. Dong, H. Schnablegger, M.A. Katsoulakis, E. Kokkoli, A. V. McCormick, R. L. Penn, M., Tsapatsis, Mechanistic principles of nanoparticle evolution to zeolite crystals. Nat. Mater. 5 (2006) 400-408.

[43] S. Kumar, Z. Wang, R. Lee Penn, M. Tsapatsis, A structural resolution cryo-TEM study of the early stages of MFI growth. J. Am. Chem. Soc. 130 (2008) 17284-17286.

[44] E. Beniash, J. Aizenberg, L. Addadi, S. Weiner, Amorphous calcium carbonate transforms into calcite during sea urchin larval spicule growth. Proc. R. Soc. B-Biol. Sci. 264 (1997) 461-465. 
[45] Y. U. T. Gong, C. E. Killian, I. C. Olson, N. P. Appathural, A. L. Amasino, M. C. Martin, L. J. Holt, F. H. Wilt, P. U. P. A. Gilbert, Phase transitions in biogenic amorphous calcium carbonate. Proc. Natl. Acad. Sci. U.S.A. 109 (2012) 6088-6093.

[46] A. J. Ragauskas, G. T. Beckham, M.J . Biddy, R. Chandra, F. Chen, M. F. Davis, B. H. Davison, R. A. Dixon, P. Gilna, M. Keller, P. Langan, Lignin valorization: improving lignin processing in the biorefinery. Science 344 (2014) 1246843.

[47] A. K. Deepa, P. L. Dhepe, Lignin depolymerization into aromatic monomers over solid acid catalysts. ACS Catalysis 5 (2014) 365-379.

[48] K. Staerk, N. Taccardi, A. Boesmann, P. Wasserscheid, Oxidative depolymerization of lignin in ionic liquids. ChemS ${ }_{U}$ SChem 3 (2010) 719-723.

[49] Q. Song, F. Wang, J. Cai, Y. Wang, J. Zhang, W. Yu, J. Xu, Lignin depolymerization (LDP) in alcohol over nickel-based catalysts via a fragmentation-hydrogenolysis process. Energy Environ. Sci. 6 (2013) 994-1007.

[50] R. Ma, W. Hao, X. Ma, Y. Tian, Y. Li, Catalytic Ethanolysis of Kraft Lignin into High-Value Small-Molecular Chemicals over a Nanostructured $\alpha$-Molybdenum Carbide Catalyst. Angew. Chem. Int. Ed. 53 (2014) 7310-7315.

[51] A. Stanislaus, B. H. Cooper, Aromatic hydrogenation catalysis: a review. Catal Rev Sci Eng 36 (1994) 75-123.

[52] T. Tang, C. Yin, L. Wang, Y. Ji , F. Xiao, Good sulfur tolerance of a mesoporous Beta zeolite-supported palladium catalyst in the deep hydrogenation of aromatics. J Catal 257 (2008) 125-133.

[53] H. H. Schobert, Development of an advanced, thermally stable, coal-based jet fuel. Fuel Process Technol 89 (2008) 364-378.

[54] J. Park, J. Lee, J. Miyawaki, Y. Kim, S. Yoon, I. Mochida, Hydro-conversion of 1-methyl naphthalene into (alkyl)benzenes over alumina-coated USY zeolitesupported NiMoS catalysts. Fuel 90 (2011) 182-189.

[55] H. Yasuda, T. Sato, Y. Yoshimura, Influence of the acidity of USY zeolite on the sulfur tolerance of Pd-Pt catalysts for aromatic hydrogenation, Catal Today 50 (1999) 63-71.

[56] B. Pawelec, R. Mariscal, R. M. Navarro, S. Van Bokhorst, S. Rojas, J. L. Fierro, Hydrogenation of aromatics over supported Pt-Pd catalysts. Appl Catal A 225 (2002) 223237.

[57] A. H. Janssen, A. J. Koster, K. D. Jong, On the shape of the mesopores in zeolite Y: a three-dimensional transmission electron microscopy study combined with texture analysis. J Phys Chem B 106 (2002) 11905-11909.

[58] A. Corma, A. Martínez, V. Martínez-Soria, Catalytic performance of the new delaminated ITQ-2 zeolite for mild hydrocracking and aromatic hydrogenation processes. J Catal 200 (2001) 259-269.

[59] G. T. M. Kadja, R. R. Mukti, Z. Liu, M. Rilyanti, Ismunandar, I. N. Marsih, M. Ogura, T. Wakihara, T. Okubo, Mesoporogen-free synthesis of hierarchically porous ZSM-5 below $100^{\circ} \mathrm{C}$, Microporous Mesoporous Materials, 226 (2016) 344-352. 


\section{Graphical Abstract}

Hierarchical zeolites with MFI structure are synthesized by solid-state crystallization of aluminosilicate nanogels without the involvement of meso-template. After transforming within nanogels using only intrinsic water storage, the new formed nanocrystals further joint each other at edges into monolithic zeolites to create many inter-crystal mesopores. The produced mesoporous ZSM-5 zeolites exhibits superior stability and catalytic performance in benzylation, lignin ethanolysis, and naphthalene hydrogenation.

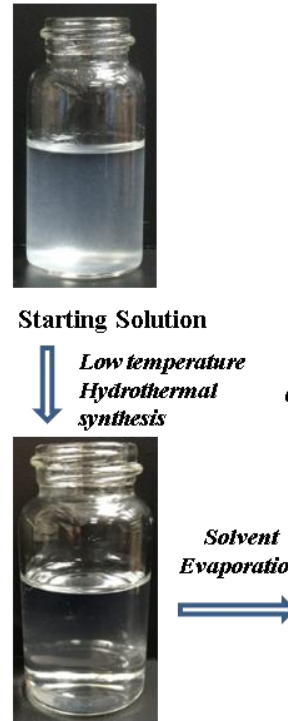

Aluminosilicat Nanogels

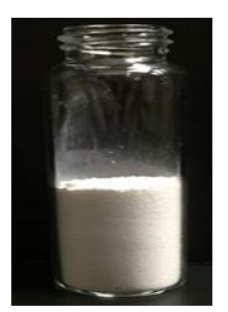

Hierarchical Zeolites

Solia-state Coystallization

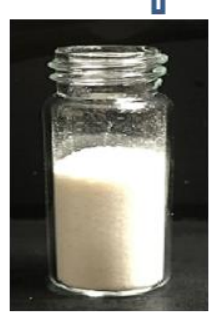

Dry Aluminosilicat Nanogels
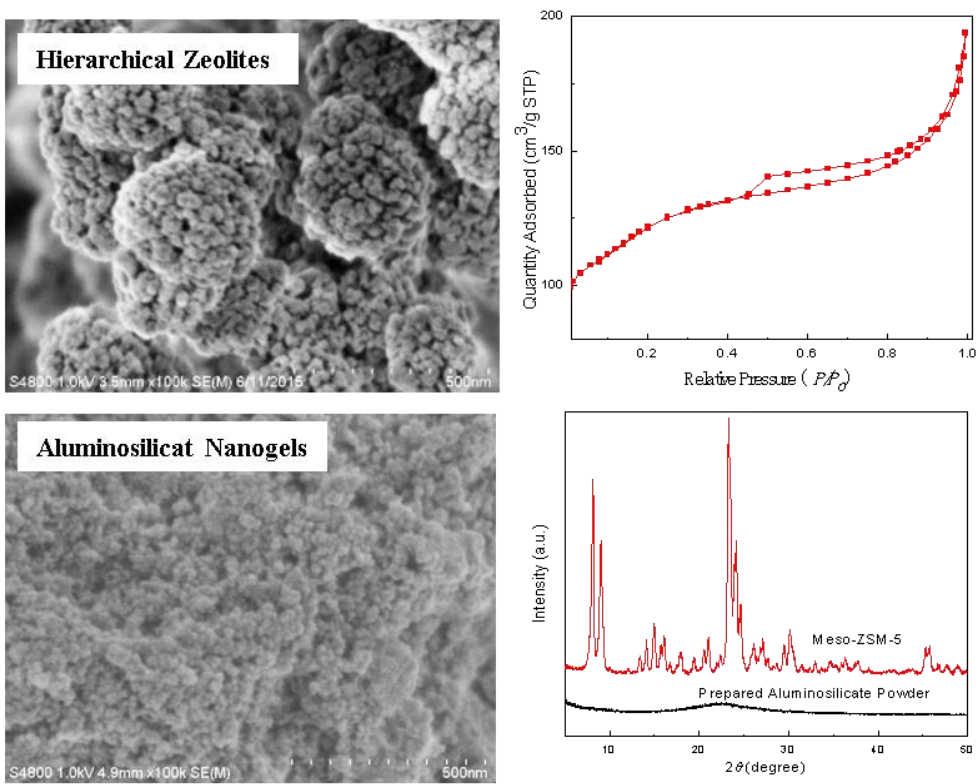

$[60]$ 